
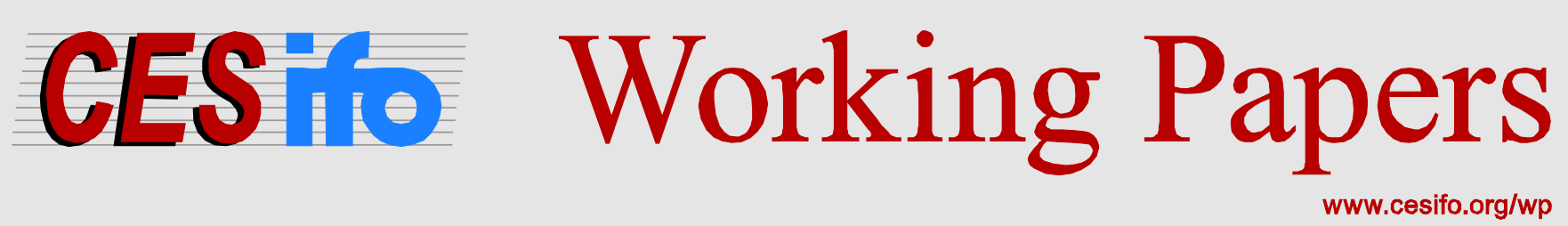

\title{
The Trade-off between Intra- and Intergenerational Equity in Climate Policy
}

\author{
Snorre Kverndokk \\ Eric Nævdal \\ Linda Nøstbakken
}

\author{
CESIFO WORKING PAPER NO. 4285 \\ CATEGORY 10: ENERGY AND ClimATE ECONOMICS \\ ORIGINAL VERSION: JUNE 2013 \\ THIS VERSION: DECEMBER 2013
}

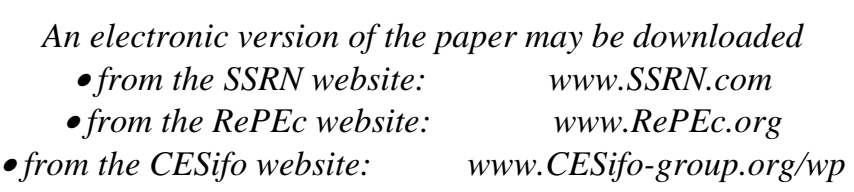




\title{
The Trade-off between Intra- and Intergenerational Equity in Climate Policy
}

\begin{abstract}
This paper focuses on two equity dimensions of climate policy, intra- and intergenerational, and analyzes the implications of equity preferences on climate policy, and on the production and consumption patterns in rich and poor countries. We develop a dynamic two-region model, in which each region suffers from global warming, but also has an inequality aversion over current consumption allocations. Inequality aversion generally lifts the consumption path of the poor region, while the rich region must take a greater share of the climate burden. Furthermore, with inequality aversion, the optimal climate policy generally leads to higher investment in clean capital in the North and in dirty capital in the South, thereby allowing the South to pollute more and develop faster. The optimal policy may even require the poor region to increase emissions relative to the uncoordinated business-as-usual case. Introducing local pollution, transfers and loans confirm the main results. However, loans to poor countries to reduce inequality may result in permanent inequality, and hence, debt remittance may be part of the optimal climate policy.
\end{abstract}

JEL-Code: C630, D310, D630, Q540.

Keywords: intragenerational equity, intergenerational equity, inequality aversion, climate policy, economic development, local pollution, international transfers.

Snorre Kverndokk (corresponding author)

The Ragnar Frisch Centre for Economic Research

Gaustadallèen 21

Norway - 0349 Oslo

snorre.kverndokk@frisch.uio.no

\author{
Eric Ncevdal \\ The Ragnar Frisch Centre for \\ Economic Research / Oslo / Norway \\ eric.navdal@frisch.uio.no
}

\author{
Linda Nøstbakken \\ Norwegian School of Economics \\ Bergen / Norway \\ linda.nostbakken@nhh.no
}

December 2013

This paper is funded by the MILJØ2015 program at the Research Council of Norway. We have benefited from discussions with Geir Asheim, Johan Eyckmans, Samuel Fankhauser, Reyer Gerlagh, Bård Harstad, Haifang Huang, Itziar Lazkano, Atle Seierstad and Emilson C.D. Silva, in addition to comments from participants at the SURED conference 2012, the CREE workshop in Oslo in September 2012, the Annual Meeting of the Norwegian Association of Economists in 2013, the AERE summer conference 2013, EAERE 2013, EEA-ESEM 2013, as well as a referee, an associate editor and the editor of the journal. The authors are associated with CREE - the Oslo Centre for Research on Environmentally Friendly Energy - which is supported by the Research Council of Norway. 


\section{Introduction}

While most scientists and politicians have recognized climate change as a threat to the future for many years, there is still an ongoing debate as to what to do about it. Researchers may not agree on the optimal emissions reductions even if they agree on the natural science background, the impacts and the costs of abating greenhouse gas emissions. One important reason is that optimal emission reductions depend on equity issues, and our discounting of future climate impacts is particularly important. However, ethical issues have not been fully explored in economic analyses, as greenhouse gas abatement not only affects the welfare distribution between present and future generations, but also the distribution within a generation, such as between rich and poor countries. These two equity dimensions are important when studying optimal emissions reductions, and as we explain below, they may work in different directions.

The purpose of our study is to analyze the trade-off between the two dimensions of equity in climate policy. We ask the following question: How should we design climate policies when people have preferences for both equity dimensions, and what are the implications for emissions and energy investments?

These dimensions of equity can be referred to as intra- and intergenerational. The first is primarily about how we should distribute the burdens within a generation, either within the generation living today or within future generations, see Kverndokk and Rose (2008). Two examples of this can be: who would suffer from climate change (inaction), and how should the burdens of mitigation (action) be distributed? In the years to come, the world may face large climatic changes, such as increased temperatures, sea level rise, changed wind and precipitation patterns, and more extreme weather (IPCC, 2013). However, the associated damages will not be evenly distributed among countries or within a given country. Studies by Tol et al. (2000), Tol (2002a,b) and Yohe et al. (2007) show that some sectors will lose from climate change while others will benefit. Poorer countries are likely facing relatively stronger negative impacts than richer countries. In addition, several studies suggest that the costs of action will vary across countries and sectors, and that abatement is generally more expensive in more energy efficient economies (IPCC, 2007). Policy instruments implemented to reduce greenhouse gas emissions will impose different burdens on people, and economic instruments 
such as carbon taxes will often be regressive, so that the poorest will face the highest burden (see, e.g., Bye et al., 2002).

While intragenerational equity is important, most of the equity debate related to climate change in the economic literature has been on intergenerational issues. This debate has focused on the size of emissions reductions to aim for, and on what should be the upper limit on the atmospheric greenhouse gas concentration or the global mean temperature. These questions also affect the distribution of burdens between the current generation and future generations, as the costs of mitigation are borne by the current generation, while future generations benefit from it. According to the literature, there are several reasons for extensive mitigation today, such as attitudes toward risk and concerns about catastrophic events (Weitzman, 2007a). However, most of the discussions have been about the appropriate discount rate for climate policy decisions, as the optimal abatement level is very sensitive to this parameter (Nordhaus, 2007; Weitzman, 2007b; Dasgupta, 2008), which again represents ethical choices. ${ }^{1}$ Intergenerational aspects of climate change have also been studied by John and Pecchenino with coauthors (John and Pecchenino, 1994; John et al., 1995) who focus on the tradeoff between economic growth and environmental quality.

Most studies treat intra- or intergenerational equity separately. However, choices that affect intergenerational distribution also affect the intragenerational distribution between rich and poor countries. As Heal (2009) points out, there are at least two ways in which preferences for equality affect the choice of climate action. First, if we believe that consumption increases over time, a high elasticity of marginal utility of consumption leads to less aggressive action. The reason is that this makes future generations richer, and if we care about inequality between the present and future generations, we place a lower value on the future rich (intergenerational equity). There is, however, an additional effect. The poor countries are likely to suffer the most from climate change. Hence, if we put a low weight on future outcomes, climate change is more likely to occur and hit poor countries hard

\footnotetext{
${ }^{1}$ The consumption discount rate used in economic analyses depends on the pure rate of time preference (utility discounting) and the elasticity of the marginal utility of consumption, which both represent equity choices. In addition, if a stock variable such as the environment enters the utility function, we get another term in the consumption discount rate that depends on the elasticity of the marginal utility of consumption with respect to the level of the stock, see, e.g., Heal (2007). Again, this variable represents an equity choice.
} 
(intragenerational equity). Consequently, the gap between the welfare levels of the rich and the poor may be wider, and based on the latter effect, stronger preferences for equality should go in the direction of more action to prevent climate change.

These two effects of inequality aversion work in different directions, and the impacts of stronger preferences for equity on the level of greenhouse gas abatement are ambiguous. However, global models used to determine the optimal level of greenhouse gas emissions focus on the first effect (intergenerational), implying that stronger preferences for equality induce low abatement (see e.g., Nordhaus and Boyer, 2000). ${ }^{2}$

Schelling (1992) suggested one solution to this by arguing that the best way to reduce the impacts of global warming is development of the poor region. The developed world is not as vulnerable to climate change due to their high level of economic development. We can, therefore, reduce the vulnerability of poorer countries by letting them develop. The end result may then be that the world is not hit as hard by climate change, while economic differences between regions are reduced. Apart from Schelling, few economists have discussed the linkages between the two equity dimensions. However, recently, Baumgärtner et al. (2012) provided a general discussion about the trade-offs between inter- and intragenerational equity in economic analysis, while Glotzbach and Baumgärtner (2012) analyze the relationship between these two aspects in ecosystem management. We are not aware of any studies of optimal climate policy that take both types of inequality aversion into account when investigating the impacts on emissions and investments in clean and dirty capital. Our paper aims to close this gap.

In this paper, we set up a simple model with two regions, a rich and a poor, to explicitly account for equity preferences along the two dimensions. The intergenerational aspect is the trade-off between welfare for present and future generations due to the impacts of global warming, while the intragenerational aspect is purely a developmental issue as we compare the consumption levels of the poor and the rich. We use the Fehr and Schmidt (1999) framework to express the latter concern, as it is supported by a recent experiment with participants who have been involved in international climate policy (Dannenberg et al., 2010).

\footnotetext{
${ }^{2}$ These models often apply Negishi weights that freeze the current distribution of income, meaning that intragenerational distribution is not considered (Stanton, 2011).
} 
We do not study differences in vulnerability to climate damage across countries as discussed by Schelling (1992), but focus on the implications of economic development in the poor region for emissions and capital investments. Our main finding is that preferences for intragenerational equality shift the climate burden towards the rich region; the poor region should generally use the more productive dirty capital to speed up its development, while the rich region should carry most of the abatement burden. Since clean capital is less productive by assumption, the consumption in the rich region falls and increases in the poor region. Hence, this result supports the claims made by developing countries in global climate negotiations, that emissions reductions will cause setbacks on the road to development.

The paper is organized in the following way. In the next section, we study the optimal climate policy when people have preferences for both intra- and intergenerational equity, while Section 3 compares this outcome to the Business-as-Usual case (no social contract). In Section 4 we introduce some extensions and analyze the implications of direct transfers, loans and local pollution under the social contract. We illustrate our results with numerical simulations of the optimal climate policy in Section 5. The final section concludes.

\section{Deciding on the Social Contract: A Model of Inequality Aversion}

As a starting point, we study the optimal global climate contract. To do this, we take a consequentialist standpoint and consider the aggregate welfare of individuals as the social objective. Hence, the social contract maximizes a social welfare function.

\subsection{The Basics of the Model}

Consider two regions $n$ and $s$, where $n$ denotes the developed region (North) and $s$ the developing region (South). The welfare of a representative consumer/country in region $r=n, s$ at time $t$ is:

$$
U_{r, t}=u\left(c_{r, t}, S_{t}\right)-\alpha \max \left(c_{k, t}-c_{r, t}, 0\right)-\beta \max \left(c_{r, t}-c_{k, t}, 0\right), \quad r, k=n, s, \quad r \neq k,
$$

where $c_{r, t}$ is consumption, and $S_{t}$ is the state of the global environment, while $k$ denotes the other region. $u\left(c_{r, t}, S_{t}\right)$ is a standard utility function that is increasing and concave in $c_{r, t}$ and 
$S_{t}$, and has the property: $\lim _{c_{r, t} \rightarrow 0} \frac{\partial u\left(c_{r, t}, S_{t}\right)}{\partial c_{r, t}}=\infty$. Furthermore, we assume that consumption and environmental quality are complements: $\frac{\partial U\left(c_{r, t}, S_{t}\right)}{\partial c_{r, t} \partial S_{t}} \geq 0$. As mentioned above, we do not consider different degrees of vulnerability to climate change between the two regions.

We model preferences for equality as inequality aversion following Fehr and Schmidt (1999). This implies that people dislike having higher consumption than others, but they dislike even more to consume less than others. ${ }^{3}$ This streamlines the economic development perspective as the intragenerational aspect. In contrast, the climate change perspective is the intergenerational aspect in our model. The Fehr and Schmidt framework has primarily been used to describe preferences for income equality among individuals, but may also be useful as a description of the social preferences of policy makers in different regions, as long as the transfers between regions are not due to strategic reasons only. ${ }^{4}$

Following this, let $\alpha$ be a parameter representing the negative feeling of being worse off than others, while $\beta$ is the parameter representing the negative feeling of being better off. We then have that $\alpha \geq \beta \geq 0$. We ignore strategic interactions by assuming that each region, North and South, consists of many identical countries that do not have any market power and cannot individually affect the overall level of global environmental quality.

Note that since the utility function is increasing and concave in consumption, a social planner seeking to maximize the sum of welfare over the two regions will reduce inequality in consumption as this increases aggregate welfare. Hence, even without the Fehr-Schmidt inequality aversion in the utility function (1), there are gains from eliminating intragenerational inequality. However, this is not driven by aversion towards inequality per

\footnotetext{
${ }^{3}$ This assumption is in contrast to the result from one experiment with participants who have been involved in international climate policy. Dannenberg et al. (2010) find that participants dislike to a considerable extent being better off than others, while their aversion to being worse off than others is moderate. However, this does not have any implications for the analyses below.

${ }^{4}$ Other alternative social preferences could be used, but this is not crucial to our conclusions as long as they express preferences for equality in payoffs such as consumption. One example is Charness-Rabin preferences (Charness and Rabin, 2002) applied by Kolstad (2011) to study coalitions in public goods provision.
} 
$s e$, but by the desire to maximize aggregate utility. This is done by allocating resources for consumption where they yield the highest return. Also, these gains are only present in the social planner case: the concavity of the utility function does not give individual countries incentives to reduce intragenerational inequality, as countries only care about their own welfare, not aggregate global welfare.

Without loss of generality, let us assume that the population sizes of the two regions are equal and normalized to unity. Therefore, $c_{r, t}$ is per capita consumption in region $r$ in period $t$. Furthermore, each representative country produces an aggregate good, $Y_{r, t}$, using clean and dirty inputs, $Y_{r, j, t}, j=c, d$, which are perfect substitutes: ${ }^{5}$

$$
Y_{r, t}\left(K_{r, c, t}, K_{r, d, t}\right)=Y_{r, c, t}\left(K_{r, c, t}\right)+Y_{r, d, t}\left(K_{r, d, t}\right), \quad r=n, s
$$

where subscripts $c$ and $d$ denote clean and dirty, respectively. The clean input is produced with clean capital, $K_{r, c, t}$, while the dirty input is produced with dirty capital, $K_{r, d, t}$. We assume diminishing marginal returns in both production processes and constant total factor productivities.

Initially, the North has more of both types of capital than the South: $K_{n, j, 0}>K_{s, j, 0}$, for $j=c, d$. Indeed, given that preferences and technology are the same in both regions, North's larger initial stock of capital defines it as the richer region, but the regions are identical in all other aspects.

Each country can invest in clean and dirty capital, with capital dynamics given by:

$$
K_{r, j, t+1}=\left(1-\delta_{j}\right) K_{r, j, t}+I_{r, j, t}, r=n, s, j=c, d,
$$

where $\delta_{j}$ is the capital depreciation rate.

The countries' resource constraints are: ${ }^{6}$

\footnotetext{
${ }^{5}$ One example can be electricity.

${ }^{6}$ Note that we do not explicitly model markets. This can be justified by imagining a sequence of spot markets that are renewed across generations.
} 


$$
Y_{r, t}\left(K_{r, c, t}, K_{r, d, t}\right)=c_{r, t}+I_{r, c, t}+I_{r, d, t}, \quad r=n, s
$$

By substituting for investment, $I_{r, c, t}$ and $I_{r, d, t}$, from equation (3), we can write the resource constraint of a country in region $r$ as:

$$
Y_{r, t}\left(K_{r, c, t}, K_{r, d, t}\right)=\left[K_{r, c, t+1}-\left(1-\delta_{c}\right) K_{r, c, t}\right]+\left[K_{r, d, t+1}-\left(1-\delta_{d}\right) K_{r, d, t}\right]+c_{r, t}, \quad r=n, s .
$$

We model the global environment as a stock variable that deteriorates with global pollution (e.g., climate change), which follows from the aggregate use of the dirty capital, assuming a constant emissions factor $\kappa>0$, and regenerates naturally at a rate $1>\sigma>0$ :

$$
S_{t+1}=\sigma \bar{S}+(1-\sigma) S_{t}-\kappa \sum_{r} K_{r, d, t}
$$

The equation implies that the global environmental quality satisfies the following constraint: $S_{t} \in[0, \bar{S}]$, where $\bar{S}$ is the long-run level in absence of pollution. Note that without pollution, $S_{t}$ converges asymptotically to $\bar{S}$. We therefore treat climate change as a reversible process in the very long run.

\subsection{The Social Contract}

The social planner seeks to maximize the sum of discounted welfare across regions, where welfare in period $t$ is given by:

$$
W_{t}=u\left(c_{n, t}, S_{t}\right)+u\left(c_{s, t}, S_{t}\right)-(\alpha+\beta)\left[\max \left(c_{n, t}-c_{s, t}, 0\right)+\max \left(c_{s, t}-c_{n, t}, 0\right)\right]
$$

It is important to note that $W_{t}$ is not differentiable when $c_{n, t}=c_{s, t}$ because of the maxoperator. However, $W_{t}$ is right differentiable, which is all that is required for constrained maximization to work. We can calculate the following derivatives when $c_{n, t}=c_{s, t}$ :

$$
\begin{aligned}
& \frac{d}{d c_{r, t}}\left\{(\alpha+\beta) \max \left(c_{r, t}-c_{k, t}, 0\right)\right\}=\alpha+\beta, \quad r \neq k \\
& \frac{d}{d c_{k, t}}\left\{(\alpha+\beta) \max \left(c_{r, t}-c_{k, t}, 0\right)\right\}=0, \quad r \neq k
\end{aligned}
$$

The social planner seeks to find the consumption and investment paths for each region that maximize the sum of discounted welfare given by equation (7): 


$$
\max _{\left\{c_{n t}, c_{s t}, K_{n c t+1}, K_{s c t+1}, K_{n d t+1}, K_{s d l+1}, S_{t+1}\right\}} \sum_{t=0}^{\infty} \rho^{t}\left\{\sum_{r} u\left(c_{r, t}, S_{t}\right)-\phi \max \left(c_{n, t}-c_{s, t}, 0\right)-\phi \max \left(c_{s, t}-c_{n, t}, 0\right)\right\}
$$

subject to the production function (2), resource constraint (5), and the dynamics of environmental quality (6), where $\rho=1 /(1+v)$ is a discount factor, $v>0$ is the pure time preference rate, and $\phi \equiv \alpha+\beta \geq 0$ is a constant. These parameters represent the main preferences for inter- and intragenerational equity in the model.

We can now express the Lagrangian of the maximization problem (9) as follows: ${ }^{8}$

$$
\begin{aligned}
\mathcal{L}_{s o} & =\sum_{t=0}^{\infty} \rho^{t}\left\{\sum_{r} u\left(c_{r, t}, S_{t}\right)-\phi \max \left(c_{n, t}-c_{s, t}, 0\right)-\phi \max \left(c_{s, t}-c_{n, t}, 0\right)\right. \\
& +\sum_{r} \lambda_{r, t}\left[Y_{r, t}\left(K_{r, c, t}, K_{r, d, t}\right)-K_{r, c, t+1}+\left(1-\delta_{c}\right) K_{r, c, t}-K_{r, d, t+1}+\left(1-\delta_{d}\right) K_{r, d, t}-c_{r, t}\right] \\
& \left.+\mu_{t}\left[\sigma \bar{S}+(1-\sigma) S_{t}-\kappa \sum_{r} K_{r, d, t}-S_{t+1}\right]\right\}
\end{aligned}
$$

given that $S_{0}=\bar{S}_{0} \leq \bar{S}, K_{r, j, 0}=\bar{K}_{r, j, 0}$, and $\bar{K}_{n, j, 0}>\bar{K}_{s, j, 0}$, for $j=c, d$ and $r=n, s$. Furthermore, $\lambda_{r, t} \geq 0$ is the shadow price of capital in region $r$ while $\mu_{t} \geq 0$ is the shadow price of environmental quality in period $t$.

Below, we show that the optimal consumption paths of the two regions must satisfy $c_{n, t} \geq c_{s, t}$, and for ease of exposition we use this to simplify the first order conditions. ${ }^{9}$ These conditions include:

$\left[c_{n, t}\right]:$

$$
\begin{gathered}
{\left[c_{n, t}\right]:} \\
\frac{\partial u\left(c_{n, t}, S_{t}\right)}{\partial c_{n, t}}-\phi=\lambda_{n, t} \\
c_{n, t}>c_{s, t} \Leftrightarrow \frac{\partial u\left(c_{s, t}, S_{t}\right)}{\partial c_{s, t}}+\phi=\lambda_{s, t} \\
c_{n, t}=c_{s, t} \Leftrightarrow \frac{\partial u\left(c_{s, t}, S_{t}\right)}{\partial c_{s, t}}-\phi \leq \lambda_{s, t} \\
{\left[K_{r, d, t+1}\right]: \quad \lambda_{r, t+1}\left[\frac{\partial Y_{r, t+1}\left(K_{r, c, t+1}, K_{r, d, t+1}\right)}{\partial K_{r, d, t+1}}+1-\delta_{d}\right]-\mu_{t+1} \kappa=\rho^{-1} \lambda_{r, t}, r=n, s}
\end{gathered}
$$$$
\left[c_{s, t}\right]:
$$

\footnotetext{
${ }^{8}$ See, e.g., Conrad and Clark (1987).

${ }^{9}$ The complete conditions would require two conditions in (11) in the same manner as in equation (12).
} 


$$
\begin{array}{cc}
{\left[K_{r, c, t+1}\right]:} & \lambda_{r, t+1}\left[\frac{\partial Y_{r, t+1}\left(K_{r, c, t+1}, K_{r, d, t+1}\right)}{\partial K_{r, c, t+1}}+1-\delta_{c}\right]=\rho^{-1} \lambda_{r, t}, r=n, s \\
{\left[S_{t+1}\right]:} & \sum_{r} \frac{\partial u\left(c_{r, t+1}, S_{t+1}\right)}{\partial S_{t+1}}=\rho^{-1} \mu_{t}-(1-\sigma) \mu_{t+1}
\end{array}
$$

In addition, the following transversality conditions must hold:

$$
\begin{gathered}
\lim _{t \rightarrow \infty} \rho^{t} \lambda_{r, t} K_{r, j, t}=0, \text { for } r=n, s, j=c, d \\
\lim _{t \rightarrow \infty} \rho^{t} \mu_{t} S_{t}=0
\end{gathered}
$$

Clearly, an important question when analyzing the optimal solution is whether consumption in the two regions will converge to the same level in the long run. In Appendix 1, we show that this will be the case, which gives us Lemma 1 .

Lemma 1. In the long run, the socially optimal consumption levels and capital stocks of the two regions will converge independently of inequality aversion.

Proof: See Appendix 1.

Note that the result is independent of inequality aversion in consumption. As discussed above, diminishing marginal utility of consumption and declining marginal productivity will ensure equality in the long run. However, inequality aversion affects the convergence process, as we discuss below and show with numerical simulations in Section 5 .

\subsection{Optimal Policy}

We first characterize the social planner solution. Later we use this as our basis when we analyze how inequality aversion affects the optimal consumption and capital paths of the two regions. We start out by characterizing the two region's optimal capital paths. We summarize the main findings in Lemmas 2-5, before we discuss the implications of these results.

Lemma 2. $\lambda_{n, t} \leq \lambda_{s, t}, \forall t$ : The shadow price of the resource constraint is higher in the South than in the North along the optimal path. 
Proof: This follows from the concavity of the value function in the optimization problem. $\lambda_{n, t}$ and $\lambda_{s, t}$ are the shadow prices of the aggregate capital levels of the two regions. Because the value function is concave and the shadow prices are the derivatives of the value function with respect to the state variables, we know that $\frac{\partial \lambda_{r}}{\partial K_{r}} \leq 0$, where $K_{r} \equiv K_{r, c}+K_{r, d}$ Since $K_{n, t} \geq K_{s, t}, \forall t$, then it must be the case that $\lambda_{n, t} \geq \lambda_{s, t}, \forall t$

To better see why Lemma 2 must hold, note that there are no constraints on investment or disinvestment. This means that each country can adjust its share of clean (and thus dirty) capital as it wishes in any period. Hence, each country is constrained by its total stock of capital, and the lower this capital stock is, all else equal, the higher the shadow price of the resource constraint (capital). Since the North is richer than the South, the South's shadow price of capital must exceed the North's.

Lemma 3. $K_{n, c, t} \geq K_{s, c, t}, \forall t$ : The North carries most of the climate burden by holding more clean capital than the South.

Proof: We rewrite the optimality conditions for clean and dirty capital as follows:

$$
\begin{gathered}
M P_{r, c, t+1}+1-\delta_{c}=\frac{\lambda_{r, t}}{\rho \lambda_{r, t+1}}, \\
M P_{r, d, t+1}+1-\delta_{d}-\kappa \frac{\mu_{t+1}}{\lambda_{r, t+1}}=\frac{\lambda_{r, t}}{\rho \lambda_{r, t+1}}
\end{gathered}
$$

where we have used the notation $M P_{r, j, t} \equiv \frac{\partial Y_{r, t}\left(K_{r, j, t}, K_{r, j, t}\right)}{\partial K_{r, j, t}}$. Noting that the term $\mu_{t+1} \kappa$ in (19) is independent of region, we isolate this term, substitute in for $\lambda_{r, t}$, and combine conditions (19) for $r=n, s$. This gives us the following relationship that must hold along the optimal path to steady state:

$$
\frac{\lambda_{n, t+1}}{\lambda_{\mathrm{s}, t+1}}=\frac{M P_{s, d, t+1}-M P_{s, c, t+1}-\left(\delta_{d}-\delta_{c}\right)}{M P_{n, d, t+1}-M P_{n, c, t+1}-\left(\delta_{d}-\delta_{c}\right)}
$$


We know from Lemma 2 that the shadow price of the resource constraint is higher in the poorer region, hence, $\lambda_{n, t} \leq \lambda_{s, t}, \forall t$. This implies that the denominator of (20) is larger than the numerator also for the term on the right-hand side. Using this and simplifying yield:

$$
M P_{n, c, t}-M P_{s, c, t} \leq M P_{n, d, t}-M P_{s, d, t} .
$$

Now assume that the lemma does not hold and that $K_{n, c, t}<K_{s, c, t}$ for some $t$. This would imply that $M P_{n, c, t}>M P_{s, c, t}$. However, since $\lambda_{n, t} \leq \lambda_{s, t}$, the North must still be richer than the South, and hence, $K_{n, d, t}>K_{s, d, t}$ so that $M P_{n, d, t}<M P_{s, d, t}$. However, the inequality (21) does not hold for $M P_{n, c, t}>M P_{s, c, t}$ and $M P_{n, d, t}<M P_{s, d, t}$. It follows that $K_{n, c, t} \geq K_{s, c, t}, \forall t$.

Note that equations (18) and (19) imply that even if the capital depreciation rates for clean and dirty capital are equal, we will require a higher marginal productivity from dirty than clean capital to invest. To see this clearer, we can setup the first-order conditions for clean and dirty capital in steady state: $M P_{c}=\delta_{c}+v$ and $M P_{d}=\frac{\mu \kappa}{\lambda}+\delta_{c}+v$. While the optimal level of clean capital requires its marginal productivity to equal the sum of the depreciation and discount rates, the marginal productivity of dirty capital must also cover the welfare effects of increased pollution. This is captured by the term $\mu \kappa / \lambda$, which is the reduction in environmental quality from an additional unit of dirty capital measured in consumption. ${ }^{10}$ Before the system reaches the steady-state equilibrium, equations (18) and (19) shows that the optimal investment decision also accounts for the trade-off between investing more today, which increases future consumption possibilities, and higher consumption today as captured by the term $\lambda_{r, t} / \rho \lambda_{r, t+1}$. Once the two regions' capital levels converge, the marginal productivity of dirty capital will be the same in all countries (cf. Lemma 1).

Lemma 4. $\Delta_{t}\left(\lambda_{s, t}-\lambda_{n, t}\right) \leq 0, \forall t:$ The difference in the shadow price of the resource constraint between the North and the South decreases over time.

\footnotetext{
${ }^{10}$ As consumption and capital levels in the regions converge over time, all terms become the same for the two regions in steady state.
} 
Proof: From optimality condition (18) for $r=n, s$, and the result that $K_{n, c, t} \geq K_{s, c, t}$ (Lemma 3), we know that the following must hold:

$$
\frac{\lambda_{n, t}}{\lambda_{n, t+1}} \leq \frac{\lambda_{s, t}}{\lambda_{s, t+1}}
$$

Since $\lambda_{n, t} \leq \lambda_{s, t}$ (Lemma 2), this implies that the growth rate of the shadow price of the resource constraint is higher in the North than in the South, thereby reducing the term $\lambda_{s, t}-\lambda_{n, t}$ over time.

Lemma 5. $c_{n, t} \geq c_{s, t}, \forall t:$ The consumption level of the South never exceeds that of the North, independently of inequality aversion.

Proof: Assume that the lemma does not hold and that $c_{n, t}<c_{s, t}$ in some periods $t$. The optimality conditions for consumption, (11) and (12), now becomes: $M U_{n, t}^{c}+\phi=\lambda_{n, t}$ and $M U_{s, t}^{c}-\phi=\lambda_{s, t}$, where $M U_{r, t}^{x} \equiv \frac{\partial u\left(c_{r, t}, S_{t}\right)}{\partial x}$ with $x=c, S$. Using that $\lambda_{n, t} \leq \lambda_{s, t}$ from Lemma 2, this implies that the following must hold:

$$
M U_{s, t}^{c}-\phi>M U_{n, t}^{c}+\phi
$$

However, this can never hold for $\phi \geq 0$, since $M U_{n, t}^{c}>M U_{s, t}^{c}$ when $c_{n, t}<c_{s, t}$ due to diminishing marginal utility of consumption.

Lemmas 1-5 characterize the optimal capital and consumption paths for the two regions. Before convergence, we know that the North has more capital and therefore consumes more than the South. This inequality in capital stocks is captured by the difference in shadow prices of the two regions' resource constraints, $\lambda_{r, t}, r=n, s$. As shown in the proof of Lemma 3, the shadow price of the North's resource constraint is initially lower, but grows faster (or declines slower) than the South's shadow price. In addition, we know from Lemma 3 that while the South catches up with the North, the marginal product of clean capital is higher in the South than in the North, which implies a higher stock of clean capital in the North than in the South, $K_{n, c, t}>K_{s, c, t}$. Hence, the North starts out richer than the South, but over time the regions converge toward the same equilibrium levels of clean and dirty capital, and hence, 
consumption. When the aggregated capital stock of the South $\left(K_{s, c, t}+K_{s, d, t}\right)$ catches up with that of the North, the shadow prices of the resource constraints will also converge.

Finally, based on the analysis above we can show that the consumption inequality generally decreases over time. To see this, we can look at how the first order conditions for regional consumption levels change over time. This gives us: $M U_{r, t+1}^{c}-M U_{r, t}^{c}=\lambda_{r, t+1}-\lambda_{r, t}$, for $r=n, s$. Note that the term $\phi$ drops out when we take the difference, and hence, this equation becomes the same for both regions. Using this relationship for both regions and rearranging yield:

$$
\left(M U_{s, t+1}^{c}-M U_{n, t+1}^{c}\right)-\left(M U_{s, t}^{c}-M U_{n, t}^{c}\right)=\left(\lambda_{s, t+1}-\lambda_{n, t+1}\right)-\left(\lambda_{s, t}-\lambda_{n, t}\right) .
$$

From Lemma 2 and equation (22), we know that the term on the right-hand side must be negative. Hence, the difference between the two regions' marginal utilities from consumption must also decrease over time, implying that the difference in consumption levels is falling. ${ }^{11}$

\subsection{How Inequality Aversion Affects the Optimal Policy}

Having characterized the optimal consumption and capital paths of the two regions, let us now turn to the implications of inequality aversion. Note that inequality aversion does not change the available resources or production structure in the economies; stronger inequality aversion only increases the non-pecuniary cost of consumption inequality. Hence, stronger inequality aversion will increase the incentives to eliminate differences in consumption levels, and will generally increase consumption in the South and reduce consumption in the North compared to the case with less or no inequality aversion. However, it is not necessarily the case that the entire consumption path of the North shifts down, while the entire consumption path of the South shifts up, as there may be incentives to reduce consumption inequality in the short run at the cost of increased capital inequality and, therefore, higher consumption inequality later on. The tradeoff between inequality now or later will be affected by the level of inequality aversion. Hence, while stronger inequality aversion generally shifts the consumption path of the North down and the South up, there may be periods of time for which this may not hold.

\footnotetext{
${ }^{11}$ There is a special case in which equation (24) may not imply lower consumption inequality over time. Recall that the marginal utilities also depend on environmental quality. Hence, a rapid change in environmental quality over this period could make the left hand side of (24) negative even if consumption inequality increases slightly. This will depend on the sign and magnitude of $u_{r, t}^{c s c}$ for $r=n, s$.
} 
Indeed, for some time periods (or states of the world), stronger inequality aversion may in fact increase the consumption inequality between the regions.

To explain this, we start by discussing the different opportunities for the social planner to reduce the welfare loss from inequality aversion if this becomes more costly. First, from equation (18) and (19), we know that the marginal productivity of dirty capital relative to its depreciation rate exceeds that of clean capital. Hence, by increasing the share of clean capital in the North and the share of dirty capital in the South, the South becomes more productive and can hence consume more, all else equal. This adjustment can be done without sacrificing the environment, provided that we keep $\sum_{r} K_{r, d, t}$ constant. However, to let the South grow faster, it may be worthwhile to sacrifice the environment in the short run, thereby letting the South have an even higher share of the more productive dirty capital. This second option for reducing inequality highlights the tradeoff between reducing inequality today and sustaining environmental quality for tomorrow. In the long run, however, the equilibrium level of environmental quality is unaffected by inequality aversion. We return to this below.

The last option for reducing the welfare loss from inequality aversion is by changing consumption today by increasing or decreasing investment. We can achieve equality in consumption in any period by increasing investment in the North sufficiently for its consumption level to equal that of the South. While this is a possibility, it can only be optimal in the short run if the welfare loss from inequality today is high compared to the present value of the welfare loss from inequality tomorrow. This is because lower consumption inequality today comes at the cost of higher capital inequality, which leads to more consumption inequality in the future. At some point the North must consume the accumulated capital, since the two regions should converge to the same capital level in the long run. Consequently, the less value we place on future welfare (high discount rate), the more attractive it is to reduce consumption inequality today despite the cost of increased future inequality.

Note that the short-run reduction in consumption inequality may be optimal even without inequality aversion $(\phi=0)$. With a large degree of inequality in capital stocks and consumption levels between the North and the South initially, the marginal utility from one more unit of consumption is lower in the North. Therefore, it may be better to instead invest 
more in clean capital, thereby improving the environmental quality $S_{t+1}$, which increases South's utility from consumption (since $u_{r, t}^{c s} \geq 0$ ).

The only way to achieve equity in the long run is by shifting investments toward more clean capital in the North, and more dirty capital in the South. In the short run, however, the social planner can reduce inequality by increasing investments in the North and/or reducing investments in the South. Both options compromise equity and possibly environmental quality in the longer run, as more (less) capital means higher (lower) production that must affect consumption at some point of time. Whether this short-term fix for the equity problem is optimal and to what extent, depends on the trade-off between lower inequality in consumption today and higher inequality in capital stocks and possibly lower environmental quality tomorrow. The more value we put on the welfare of future generations relative to ourselves (low $v$ ), the smaller the short term reduction in consumption inequality, since this increases the present value of increased inequality in the future.

Accounting for each of the options for reducing inequality temporarily or permanently, gives us Proposition 2.1.

Proposition 2.1: For some $t$, we can have $\frac{\partial}{\partial \phi}\left(c_{n, t}-c_{s, t}\right)>0$ : Stronger inequality aversion may increase consumption inequality in some periods.

Proof: We show that this holds for specific parameter values in the numerical simulations presented in section 5. In particular, Figure 1 shows that the consumption inequality $\left(c_{n}-c_{s}\right)$ is larger for $\phi=1.5$ than for $\phi=1$ from $t=26$ to $t=40$.

To see why inequality aversion may increase consumption inequality in some periods (Proposition 2.1), we start by total differentiating the first order conditions for consumption with respect to $\phi$. This results in the following:

$$
\frac{\partial c_{n, t}}{\partial \phi}=\frac{1}{u_{n, t}^{c c}}\left[\frac{\partial \lambda_{n, t}}{\partial \phi}+1-u_{n, t}^{c s} \frac{\partial S_{t}}{\partial \phi}\right]
$$




$$
\frac{\partial c_{s, t}}{\partial \phi}=\frac{1}{u_{s, t}^{c c}}\left[\frac{\partial \lambda_{s, t}}{\partial \phi}-1-u_{s, t}^{c s} \frac{\partial S_{t}}{\partial \phi}\right]
$$

While it is sufficient that $\frac{\partial c_{n, t}}{\partial \phi} \geq \frac{\partial c_{s, t}}{\partial \phi}$ for some $t$, note that Proposition 2.1 holds if $\frac{\partial c_{n, t}}{\partial \phi} \geq 0$ and $\frac{\partial c_{s, t}}{\partial \phi} \leq 0$. Imposing this on equations (25) and (26), and rearranging yields the following condition:

$$
\frac{1}{u_{n, t}^{c s}}\left(\frac{\partial \lambda_{n, t}}{\partial \phi}+1\right) \leq \frac{\partial S_{t}}{\partial \phi} \leq \frac{1}{u_{s, t}^{c s}}\left(\frac{\partial \lambda_{s, t}}{\partial \phi}-1\right)
$$

We know that $\frac{1}{u_{r, t}^{c s}} \geq 0$ for $r=n, s$. Now consider the situation described above, in which the North has accumulated capital to temporarily reduce its consumption level (and consumption inequality). The more capital it has accumulated, the lower the shadow price of capital, $\partial \lambda_{n, t} / \partial \phi \leq 0$, and the more the North must subsequently increase consumption to reduce its capital stock. The larger the temporary reduction in consumption inequality through capital accumulation, the more the North must consume later on. Hence, at the stage when the North consumes its accumulated capital we have that $\partial c_{n, t} / \partial \phi \geq 0$. Turning to the South, we know that the more welfare reducing inequality aversion is (high $\phi$ ), the higher the value the capital poor South puts on capital, and hence, $\partial \lambda_{s, t} / \partial \phi \geq 0$. If these changes in the regions' shadow prices are sufficiently strong, the expression on the right-hand side of (27) will be larger than the expression on the left-hand side.

To justify that the impact of inequality aversion on environmental quality can lie between these two terms in the described situation, we take the total derivative of the optimality condition for environmental quality (15) and rearranging:

$$
\frac{\partial S_{t}}{\partial \phi}=\frac{1}{u_{n, t}^{s s}+u_{s, t}^{s s}}\left[\rho^{-1} \frac{\partial \mu_{t-1}}{\partial \phi}-(1-\sigma) \frac{\partial \mu_{t}}{\partial \phi}-u_{n, t}^{c s} \frac{\partial c_{n, t}}{\partial \phi}-u_{s, t}^{c s} \frac{\partial c_{s, t}}{\partial \phi}\right]
$$

The impact of inequality aversion on environmental quality in a period, will depend on how inequality aversion affects the shadow price of the environment (positive effect on $S_{t}$ ) and consumption levels in North and South (negative effect on $S_{t}$ ). 
Equation (28) is positive (negative) if the bracketed term is negative (positive). First, in the situation we consider, North consumes more and South consumes less because of higher inequality aversion. Hence, the sum of the two last terms in brackets can be positive or negative, depending on which of these two effects is stronger. Next, the shadow price of the environment $\mu_{t}$ can increase or decrease as we raise $\phi$. The marginal value of the environment increases as consumption levels increase due to the complementarity of consumption and the environment in the utility function. However, with opposite consumption effects in the North and the South the shadow price of the environment can increase or decrease with stronger inequality aversion, as can then the two first terms in brackets in (28). Consequently, $\partial S_{t} / \partial \phi$ can be positive, negative or zero, depending on the situation, and hence, (27) can hold.

It seems reasonable that with a bigger weight on inequality aversion, it becomes optimal to reduce inequality aversion more in the short run, even if this compromises the environment. The reason is that when consumption inequality becomes more welfare reducing on the margin (higher $\phi$ ), the relative marginal value of improved environmental quality falls, all else equal. This makes it more likely that society should sacrifice environmental quality in the short run by letting the South invest even more in dirty capital, thereby speeding up its development. Hence, we expect $\partial S_{t} / \partial \phi<0$ in the short run.

To summarize, we should sometimes let the rich (poor) region invest more (less) today to temporarily reduce equality at the cost of more inequality in the future. This is a result of discounting. This represents yet another example of the conflict between inter- and intragenerational equity. The less weight we put on future generations relative to those living today (high discount rate), the stronger the incentive to immediately eliminate inequality between people living today through investment. However, this means sacrificing intragenerational equity for certain future generations as the capital stocks of the two regions must converge toward the same level in the long run (Lemma 1). For the North, this implies that the capital that was accumulated to reduce short-run consumption must be consumed, leading to a temporary bump in consumption, and possibly increased inequality for a period of time. We return to this in our numerical analysis in Section 5. 
This discussion emphasizes the close relationship between climate action and development/growth. In international negotiations aimed at reaching a global climate agreement, developing countries have long expressed a concern that limiting their greenhouse gas emissions will hamper their development opportunities. On this basis, they argue that the developed world must bear the majority of the cost of reducing global emissions. Our analysis may justify this claim made by developing countries, and suggests that if we all care about equality, we may have to sacrifice environmental quality in the short run to allow the poorer region to grow faster by polluting more. Consequently, the rich region should bear the majority of the costs of improved environmental quality.

Finally, let us consider how inequality aversion affects the steady-state capital and consumption levels. We have stated the first-order conditions for the steady-state equilibrium in Appendix 1. Note that as the two regions converge to the same capital and consumption levels, the optimality condition for regional consumption becomes: $M U_{r}^{c}-\phi=\lambda_{r}$, for $r=n, s$. While there is no welfare loss from inequality in steady state, the inequality parameter is included because if any of the two regions marginally raise their consumption level from the steady-state level, this yields marginal loss due to inequality of $\phi$. However, we can think of inequality aversion as a non-pecuniary cost that does not affect production possibilities or resource availability. Hence, in steady state, the social planner will ensure that capital levels, environmental quality, and consumption are set so as to maximize welfare, which means that $\phi$ will not affect the steady-state equilibrium since there is equality.

Hence, inequality aversion across a generation will not affect greenhouse gas emissions in the long run. To see this, we can rearrange and express the steady-state condition for global environmental quality in terms of the shadow price of the environment:

$$
\mu=\frac{M U_{n}^{S}+M U_{s}^{S}}{\sigma+v}
$$

Equation (29) confirms that the steady-state level of global environmental quality does not depend on the regions' preferences for equality $(\phi)$. We also see that it is increasing in the marginal utility of environmental quality, which is given by the numerator in equation (29), while it decreases with the replenishment rate of the environment and the discount rate. 
The steady-state level of global environmental quality is given by equation (52) in Appendix 1. The path of environmental quality toward steady state depends on the aggregate level of dirty capital in the two regions. As seen above, inequality aversion affects the dirty capital paths, and thus emissions, before the system reaches steady state. We return to this in the numerical analysis in Section 5.

\section{What if a Contract is not Possible? The Business-as-Usual Case}

The next question is what the actions of the two regions would be if the social contract cannot be reached? Without an enforcement mechanism in place, the regions are better off following their own interest and maximizing the welfare of a representative consumer. We refer to this as the Business-as-Usual problem (BAU), i.e., the optimization problem of local policy makers when there is no coordinated action or global environmental agreement within or across the regions.

\subsection{The BAU Paths}

To find the BAU paths for the two regions, we first define the Lagrangians. We set the discount factor, $\rho<1$, equal for the two regions to avoid having the effects of inequality aversion confounded by the effects of discounting. ${ }^{12}$ The Lagrangian for region $r$ is:

$$
\begin{aligned}
\mathcal{L}_{r, B A U}= & \sum_{t=0}^{\infty} \rho^{t}\left\{\left[u\left(c_{r, t}, S_{t}\right)-\beta \max \left(c_{r, t}-c_{k, t}, 0\right)-\alpha \max \left(c_{k, t}-c_{r, t}, 0\right)\right]\right. \\
& \left.+\lambda_{r, t}\left[Y_{r, t}\left(K_{r, c, t}, K_{r, d, t}\right)-K_{r, c, t+1}+\left(1-\delta_{c}\right) K_{r, c, t}-K_{r, d, t+1}+\left(1-\delta_{d}\right) K_{r, d, t}-c_{r, t}\right]\right\}
\end{aligned}
$$

for $r, k=n, s, r \neq k$, where $K_{r, j, 0}=\bar{K}_{r, j, 0}$, and $\bar{K}_{n, j, 0}>\bar{K}_{s, j, 0}$, for $j=c, d$, and $\lambda_{r, t} \geq 0$ is the shadow price of capital. We assume that each country is so small that its impact on the dynamics of global environmental quality is approximately zero. As a result, we maximize (30) over consumption, and dirty and clean capital stocks, taking global environmental quality, $S_{t}$, as given. However, the dynamics of the environment still follows (6). The first order conditions then become: ${ }^{13}$

$$
\begin{array}{ll}
{\left[c_{n, t}\right]:} & c_{n, t} \geq c_{s, t} \Leftrightarrow M U_{n, t}^{c}-\beta=\lambda_{n, t} \\
& c_{n, t}<c_{s, t} \Leftrightarrow M U_{n, t}^{c}+\alpha=\lambda_{n, t}
\end{array}
$$

\footnotetext{
${ }^{12}$ For convenience, this implies using the same discounting as in the social planner case, but this does not matter for conclusions. We will also use the same symbol for the shadow price of capital; $\lambda$.

${ }^{13}$ In addition, the transversality condition (16) in Section 2 still holds.
} 


$$
\begin{array}{ccc}
{\left[c_{s, t}\right]:} & c_{n, t}>c_{s, t} \Leftrightarrow M U_{s, t}^{c}+\alpha=\lambda_{s, t} \\
& c_{n, t} \leq c_{s, t} \Leftrightarrow M U_{s, t}^{c}-\beta=\lambda_{s, t} \\
& \lambda_{r, t}=\rho \lambda_{r, t+1}\left(M P_{r, c, t+1}+1-\delta_{c}\right) \\
{\left[K_{r, c, t+1, t+1}\right]:} & \lambda_{r, t}=\rho \lambda_{r, t+1}\left(M P_{r, d, t+1}+1-\delta_{d}\right)
\end{array}
$$

We start out by characterizing the BAU solution based on the first-order conditions. Lemmas 6-9 below summarize the main results for consumption and capital dynamics. Next, we analyze and discuss the implications of the Lemmas.

Lemma 6. $c_{n, t} \geq c_{s, t} \forall t$ : Consumption in the North is higher or equal to consumption in the South along the optimal BAU path.

Proof: Assume that $c_{s, t}>c_{n, t}$. According to (31) and (32) this gives $M U_{n, t}^{c}+\alpha=\lambda_{n, t}$ and $M U_{s, t}^{c}-\beta=\lambda_{s, t}$. As follows from the proof of Lemma 2, we know that $\lambda_{n, t} \leq \lambda_{s, t}$. This gives $M U_{n, t}^{c}+\alpha \leq M U_{s, t}^{c}-\beta$, which obviously cannot hold for $c_{s, t}>c_{n, t}$. Hence, we get that $c_{n, t} \geq c_{s, t}$ along the optimal path.

Lemma 7. $K_{n, c, t} \geq K_{s, c, t} \wedge K_{n, d, t} \geq K_{s, d, t}, \forall t:$ Both capital stocks in the North are higher or equal to the capital stocks in the South along the optimal BAU path.

Proof: We know from (33) and (34) that $M P_{r, c, t+1}+1-\delta_{c}=\rho^{-1} \frac{\lambda_{r, t}}{\lambda_{r, t+1}} \quad$ and $M P_{r, d, t+1}+1-\delta_{d}=\rho^{-1} \frac{\lambda_{r, t}}{\lambda_{r, t+1}}$. Assume that the Lemma does not hold, which implies that $\frac{\lambda_{n, t}}{\lambda_{n, t+1}}>\frac{\lambda_{s, t}}{\lambda_{s, t+1}}$. This means that $M P_{n, c, t+1}>M P_{s, c, t+1}$ and $M P_{n, d, t+1}>M P_{s, d, t+1}$, and, therefore, $K_{n, c, t}<K_{s, c, t}$ and $K_{n, d, t}<K_{s, d, t}$. This cannot hold since it implies that the aggregate capital stock is lower in the North than the South, and $\lambda_{n, t}>\lambda_{s, t}$. Thus, we have that

$$
\frac{\lambda_{n, t}}{\lambda_{n, t+1}} \leq \frac{\lambda_{s, t}}{\lambda_{s, t+1}}
$$


which gives $K_{n, c, t} \geq K_{s, c, t}$ and $K_{n, d, t} \geq K_{s, d, t}, \forall t$.

In the social planner case studied in the previous section, we found that only the clean capital stock must be higher in the North than the South along the optimal path. In comparison, the North must also have a higher dirty capital stock along the BAU path. The reason for this is that no country believes it can affect the environment in the BAU case, and hence, countries in both regions invest more in dirty capital than they would if this externality was internalized as in the social planner case.

Lemma 8. Under BAU, consumption and capital stocks in the two regions converge to the same levels.

Proof: According to (35), the difference between $\lambda_{n, t}$ and $\lambda_{s, t}$ diminishes over time as long as the aggregate capital stock is higher in the North. Thus, in the long run, the economies enter a steady-state equilibrium where $\lambda_{r, t}=\lambda_{r, t+1}=\lambda_{r, B A U}^{*}$. We see then from (33) and (34) that $M P_{r, d}^{*}+1-\delta_{d}=\rho^{-1}$ and $M P_{r, c}^{*}+1-\delta_{c}=\rho^{-1}$. This means that the capital stocks are equal in steady state; $K_{n, j}^{*}=K_{s, j}^{*}=K_{j, B A U}^{*}, j=c, d$. As capital stocks and investments are constant and equal across regions in steady state, consumption is also constant and equal between the two regions: $c_{n}^{*}=c_{s}^{*}=c_{B A U}^{*}$.

Lemma 9. $M P_{r, c, t} \leq M P_{r, d, t}$ or $M P_{r, c, t}>M P_{r, d, t}, \forall t$ : The dirty technology does not have to be more productive than the clean technology along the optimal BAU path.

Proof: We see from (33) and (34) that:

$$
M P_{r, c, t+1}-M P_{r, d, t+1}=\delta_{c}-\delta_{d}
$$

Thus, the difference in marginal productivities between clean and dirty capital is determined by the depreciation rates only. If $\delta_{c}>\delta_{d}$, then $M P_{r, c, t+1}>M P_{r, d, t+1}$, while if $\delta_{c} \leq \delta_{d}$ then $M P_{r, c, t+1} \leq M P_{r, d, t+1}$.

As opposed to the social contract, under which dirty capital must be more productive than clean capital along the optimal path (ignoring depreciation effects), Lemma 8 states that this is 
no longer the case under BAU. The reason is that producers do not take into account the external environmental costs, and hence, the difference in marginal productivities is determined by the depreciation rates only.

\subsection{The Effects of Inequality Aversion on BAU paths}

Lemmas 6-9 characterize the optimal capital and consumption paths for the two regions. Note that they hold for $\alpha \geq \beta \geq 0$. Let us now study the effect of inequality aversion, i.e., $\alpha \geq \beta>0$.

Recall that the North had two main tools for helping the South in the social planner case; by reducing consumption and by contributing to better environmental quality. Under BAU, the only possibility is to reduce consumption as the North can no longer affect the marginal utility of the South, as each country takes the quality of the environment as given. Similarly, the South can only affect inequality by increasing its consumption. However, reducing consumption in the North and raising consumption in the South would lead to higher capital accumulation in the North and lower capital accumulation in the South, thereby increasing the capital inequality between the regions. Furthermore, at some stage the North must consume its accumulated capital, hence, we would get a temporary increase in consumption later on. Discounting reinforces this since a higher discount rate means that we shift weight from future to current generations. Hence, we cannot conclude that inequality aversion shifts the North's (South's) consumption path down (up) for the whole transition period toward steady state, compared the case without equality preferences $(\alpha+\beta=0)$.

To see this, consider a permanent increase in $\beta$. In a similar way as in subsection 2.4 , we find from (31):

$$
\frac{\partial c_{n, t}}{\partial \beta}=\frac{1}{u_{n, t}^{c c}}\left[1+\frac{\partial \lambda_{n, t}}{\partial \beta}-u_{n, t}^{c s} \frac{\partial S_{t}}{\partial \beta}\right] .
$$

The first term on the right hand side is the direct effect of inequality aversion, which is negative and gives an incentive to reduce consumption. The two next terms represent the indirect effects on the aggregate capital stock and the environment. The capital stock is affected as less consumption means more capital, hence $\frac{\partial \lambda_{n, t}}{\partial \beta}<0$, and the effect on consumption is positive (note $u_{n, t}^{c c}<0$ ) as having more aggregated capital means more future 
consumption, which has a negative effect on inequality. Finally, even if the regions do not take into account the environment in their decisions, environmental quality affects the BAU paths as they take the state of the environment at time $t$ into account when making investment and consumption decisions at time $t$. Thus, the effect of inequality aversion on consumption also depends on how inequality aversion affects the environment. In subsection 2.4 , we argued that most likely we have $\frac{\partial S_{t}}{\partial \beta}<0$ in the short run. This means that the effect of the environment is negative as it reduces the marginal utility of consumption. In the short run we would, therefore, expect the effect on consumption in the North to be negative. However, as capital accumulates, the second effect in (37) may be large and we may get a temporary increase in consumption. For the South we get similar effects, but with the opposite sign.

The discussion also shows that with inequality aversion in BAU, for some initial period, we get higher accumulation of clean and dirty capital in the North and lower accumulation of clean and dirty capital in the South compared to standard preferences $(\alpha+\beta=0)$. However, as some of the capital accumulation in the North has to be consumed at some point, we cannot rule out that in some intermediate periods, capital accumulation is lower with inequality aversion.

While dirty capital has to be more productive than clean capital in the social planner case (ignoring depreciation effects), this is no longer the case under BAU. An implication of this is that it is no longer possible to reduce inequality by letting the North invest relatively more in clean capital, while the South invests more in dirty. What matters under BAU are the changes in aggregate capital stocks as there are no differences in marginal productivities of clean and dirty capital, as equation (36) shows.

Let us now compare the optimal consumption levels under BAU to the socially optimal levels. Proposition 3.1 summarizes this.

Proposition 3.1: When inequality aversion within a generation reduces consumption in the North and increases consumption in the South, we get a larger consumption reduction in the North under the social contract than under BAU, while in the South we get a larger consumption increase under the social contract than under BAU. 
Proof: From subsection 2.4 we know that the effect of inequality aversion on the socially optimal $\lambda_{r, t}$ is independent of whether we increase $\alpha$ or $\beta$, as what matters is the sum: $\phi=(\alpha+\beta)$. However, we see from (31) that $\lambda_{n, t}$ is only indirectly affected by an increase in $\alpha$, and in a similar way it follows from (32) that $\lambda_{s, t}$ is only indirectly affected by an increase in $\beta$. Thus, the effect of inequality aversion on $\lambda_{r, t}$ will be higher under the social contract than under BAU. Therefore, the consumption increase (decrease) will be higher for the South (North) under the social contract than under BAU.

The intuition behind the Proposition is that each region under the social contract takes into account both regions' disutility from inequality, and not just its own disutility. Under BAU, however, the regions only care about their own disutility, while they ignore the disutility they impose on the other region. This represents an equality externality. As a consequence, stronger inequality aversion induces a larger consumption reduction in the North and a larger increase in the South under the social contract than in the BAU case, all else equal.

Without inequality aversion, consumption will in this case be lower both in the North and the South under the social contract than under BAU. The reason is that the marginal productivity of dirty capital has to be higher in the social planner case than under BAU due to the environmental externality. Thus, in the social planner case, both regions must invest less in dirty capital compared to what was optimal under BAU, and the available resources will thus be lower. If we introduce inequality aversion, we know from Proposition 3.1 that consumption generally goes down in the North both under BAU and the social contract, but that the reduction is stronger under the social contract. Therefore, the consumption level under the social contract is still lower than under BAU. However, for the South this is no longer clear as the increase in consumption under the social contract is higher than the increase under BAU. This means that it is possible that the social contract will lead to higher consumption levels in the South even if it takes into account the effects on the environment.

Let us next compare regional capital stocks between the social contract and BAU, starting with dirty capital, and hence emissions as they are proportional to dirty capital. In subsection 2.4 we argued that initially the North reduces dirty capital investments while the South 
increases them when introducing inequality aversion in the social planner case. Also, above we have argued that inequality aversion in BAU initially increases investment in dirty capital in the North, while reducing such investment in the South. Thus, the social contract yields an initial reduction in dirty capital investment in the North, while the effect in the South is ambiguous, and emissions may actually be higher under the social contract.

The intuition is as follows. The optimality condition for dirty capital under the social contract includes an additional term compared to the BAU case, see equation (13). This term represents the marginal effect of more dirty capital on global environmental quality, and implies a lower investment in dirty capital compared to BAU in both regions. However, we also have the effect of inequality aversion, which yields lower investment in dirty capital in the North and higher investment in the South. While both effects reduce dirty capital accumulation and emissions in the North, we cannot determine the effect on the capital stock in the South. Hence, poor countries should not necessarily have a pollution constraint under a global climate treaty. Under certain conditions it may actually be optimal to let poor countries increase their emissions under such treaty.

Based on this, the results for clean capital are straightforward as it follows from the discussion in subsection 2.4 and above that inequality aversion generally reduces clean capital accumulation in the South under both BAU and the social contract, while it increases clean capital accumulation in the North in both cases. This means that when preferences for equality are taken into account, the North has to make a larger contribution to combat global warming both when it comes to clean capital investments and emissions reductions.

Again, our results show that we in some cases should encourage poorer countries to use more dirty capital than they otherwise would to speed up their development.

\section{Extending the Basic Model}

Let us now turn once again to the social contract. Thus far, the only interaction between the regions has come through the impact of pollution on the global environment. Now we open up for international transfers, such as development aid or climate finance from the rich to the poor region, and loans that have to be paid back. In addition we introduce local pollution as 
local and global pollution are often interrelated, so that an increase in dirty technology may incur an extra cost to the polluting country.

\subsection{Interactions between the Regions}

When the social planner faces restriction on transfers between the regions as above, the optimal contract is a second-best policy. Consequently, when we relax the constraint by allowing for some or unlimited international transfers, the result must be that we get closer to the first-best solution and achieve higher aggregate welfare. In the following, we analyze two specific and policy relevant cases: international transfers and international loans.

\subsubsection{International Transfers}

We introduce transfers by adding the term $\tau_{t}$, which represents transfers from North to South in period $t$, to the regions' resource constraints. The two regions' modified resource constraints then become:

$$
\begin{aligned}
& Y_{n, t}\left(K_{n, c, t}, K_{n, d, t}\right)=c_{n, t}+\tau_{t}+K_{n, c, t+1}-\left(1-\delta_{c}\right) K_{n, c, t}+K_{n, d, t+1}-\left(1-\delta_{d}\right) K_{n, d, t} \\
& Y_{s, t}\left(K_{s, c, t}, K_{s, d, t}\right)=c_{s, t}-\tau_{t}+K_{s, c, t+1}-\left(1-\delta_{c}\right) K_{s, c, t}+K_{s, d, t+1}-\left(1-\delta_{d}\right) K_{s, d, t}
\end{aligned}
$$

In addition, we introduce a constraint on North-South transfers such that $\tau_{t} \leq M$ in every time period. Appendix 2 presents the modified Lagrangian for the optimization problem. Now, the social planner must also determine the optimal size of the transfers $\tau_{t}$, and hence, we obtain an additional first order condition for the North-South transfer:

$$
\lambda_{s, t}-\lambda_{n, t}=\omega_{t}
$$

where $\omega_{t}$ is the shadow price of the transfer constraint $\left(\tau_{t} \leq M\right)$. In addition, the optimality conditions for the case without transfers must still hold (equations (11)-(15)).

The optimal transfer policy is a most rapid approach path toward equality. In the case of unlimited transfers, which means that $\omega_{t}=0$ in all periods $t$, there should be a transfer from North to South in the first period that completely eliminates inequality. From the second period onward, all countries are equal and there is no welfare loss from inequality. Thus, the decision of how to split total consumption across the two regions is independent of the efficient allocation of investment. This follows from efficiency only, and inequality aversion plays no role. However, if the transfer constraint binds, condition (40) shows that the shadow 
price in the North is higher than the shadow price in the South. Hence, the optimal policy is to transfer as much as possible from North to South $\left(\tau_{t}=M\right)$ until the two regions converge. The positive shadow price of the transfer constraint illustrates the social value of development aid (direct transfers) from the rich to the poor region, which will fall over time and be zero when the two regions converge.

From Lemma 4 we know that the term $\lambda_{s, t}-\lambda_{n, t}$ will fall over time also in the case without transfers. Hence, transfers affect how rapidly the difference goes to zero. Thus, while we will reach convergence in consumption faster when transfers are allowed, the conclusions from Section 2 still holds.

\subsubsection{International Loans}

Let us now briefly investigate how the results change if aid is given in the form of loans that must be repaid with interest. The modified resource constraints (38) and (39) still hold. In addition, the net present value of payments from one region to the other must satisfy: ${ }^{14,15}$

$$
\sum_{t=0}^{\infty} \rho^{t} \tau_{t}=0
$$

In addition to conditions (11)-(15), we now add the following first order condition:

$$
\lambda_{s, t}-\lambda_{n, t}=\theta \text {. }
$$

It follows that consumption in North and South immediately are brought to levels where the difference in marginal utility of consumption is equal for all subsequent time periods. One implication of imposing this constraint is that consumption equality is not satisfied with equation (42). Hence, forcing repayment of transfers is not commensurate with achieving equality in consumption levels. However, consumption levels are instantaneously brought to the level where the difference in marginal utilities is fixed. Further loans allow for faster

\footnotetext{
${ }^{14}$ Note that the interest rate for repayment can be set by the social planner. Whether the utility discount rate or the consumption discount rate is the appropriate discount rate in (41) is debatable. We consider the present problem a global equilibrium problem, and follow the recommendation in Heal (2007) to apply the utility discount rate.

15 The model maximises the sum of concave utilities, so a no-Ponzi game constraint is not required.
} 
adjustments of capital stocks, which carries with it an efficiency gain and eliminates the need for excessive capital accumulation. ${ }^{16}$

To see the impacts of inequality aversion, we combine (11), (12) and (42) to get:

$$
\left(M U_{s, t}^{c}-M U_{n, t}^{c}\right)+2 \phi=\theta
$$

For $c_{n, t} \geq c_{s, t}, \forall t$, and as $\phi$ is fixed and $\theta$ is time independent, inequality aversion increases consumption in the South relative to consumption in the North.

If we introduce a shorter repayment period, equation (42) will no longer be valid after the loan is paid back. After completing the repayment term, we again have a situation where the North is richer than the South and we get convergence in the long run, as discussed in section 2. However, this requires the poor region to pay back faster, thereby resulting in more inequality in the medium term before the regions converge. One solution to the inequality problem that follows from repayment of loans is some sort of debt remittance, which could therefore be introduced in a social contract.

\subsection{What if Dirty Production also Causes Local Pollution?}

Let us now return to the case where direct transfers between regions are not possible, and instead look at local pollution. In many countries, particularly developing countries, people are more concerned with local pollution than with global environmental quality. Our model can be easily extended to consider both local and global pollution.

Let us assume that local pollution $D_{r, t}$ is a flow variable that, just like global environmental quality, affects people's utility from consumption: $u\left(c_{r, t}, D_{r, t}, S_{t}\right)$. The new utility function is falling in $D_{r, t}$, and has the properties: $\frac{\partial^{2} u\left(c_{r, t}, D_{r, t}, S_{t}\right)}{\partial c_{r, t} \partial D_{r, t}} \leq 0$ and $\frac{\partial^{2} u\left(c_{r, t}, D_{r, t}, S_{t}\right)}{\partial D_{r, t}^{2}} \leq 0$, in addition to the properties of the utility function we used in the analysis above. Following Silva and Zhu (2009), we assume that there is co-production of local and global pollution

\footnotetext{
${ }^{16}$ This is easily proved by noting that in steady-state equalising marginal utility of consumption leads to a contradiction.
} 
from the use of dirty capital. ${ }^{17}$ As a result, these pollutants are correlated. Let $\kappa_{l}>0$ be the coefficient that reflects the local pollution per unit of dirty capital used. Then, the flow of local pollution becomes: $D_{r, t}=\kappa_{l} K_{r, d, t}$ for $r=n, s$.

The introduction of local pollution changes the first order conditions of the welfare maximization problem slightly. First, all marginal utilities are now a function also of $D_{r, t}$. Second, the optimality condition for dirty capital (13) gets an additional term

$$
\kappa_{l} M U_{r, t+1}^{D}+\lambda_{r, t+1}\left[M P_{r, d, t+1}+1-\delta_{d}\right]-\mu_{t+1} \kappa=\rho^{-1} \lambda_{r, t}, r=n, s
$$

since more dirty capital now also affects the utility directly, as captured by the (negative) term $\kappa_{l} M U_{r, t+1}^{D}$. This will reduce dirty capital accumulation, as it requires dirty capital to have an even higher marginal productivity to justify its use. Hence, the inclusion of local pollution affects the optimal capital and consumption paths.

The optimal investment path still requires the richer North to carry more of the climate burden by investing relatively more in clean capital than the South. However, since the use of dirty capital reduces the utility from consumption, both regions will use less of it. Hence, this slows down the speed at which the South catches up with the North.

Interestingly, analyzing the case of local pollution shows that we in some cases should encourage poorer countries to use more dirty capital than they otherwise would to speed up their development. Even if poor countries ignore the negative externality of their own dirty production on the global climate, they may be reluctant to use enough dirty capital because of the negative implications for local pollution. However, the use of more dirty capital in the South speeds up this region's development, which also benefits the North because of the equality externality. Consequently, the rich world may be better off subsidizing technologies that reduces local pollution in developing countries, rather than trying to convince them to use more clean capital to cut global emissions.

\footnotetext{
${ }^{17}$ Silva and Zhu (2009) assume that pollution follows from the production of the dirty good. In our model, it follows from the use of dirty capital. In the long run (steady state), however, there is a constant relationship between production and the capital stock.
} 


\section{Numerical Simulations}

To illustrate our results, we carry out a number of simulations where we examine how inequality aversion affects the social contract.

\subsection{The Social Contract without Transfers}

In these simulations we assume that the North and the South have the same utility function given by:

$$
U\left(c_{t}, S_{t}\right)=c_{t}^{a} S_{t}^{c}
$$

Furthermore, we simulate the social contract for three values of aggregate inequality aversion, $\phi \in\{0,1,1.5\}$, over a time horizon of 150 years, although we only present the first 120 years in order to avoid end-of-horizon effects. As these simulations are for illustration only, we choose parameter values based on guesses, apart from the total factor productivities, $A_{j}$, in the production functions $Y_{r, j, t}=A_{j} K_{r, j, t}^{\gamma_{j}}, j=c, d$, which are taken from Acemoglu et al. (2012). See Appendix 3 for parameter values. ${ }^{18}$ It should be noted that the magnitude of some of the effects shown and discussed below are dependent on initial values of state variables and parameter values. Nonetheless, we have chosen the simulations below from a large number of simulations to highlight effects that are typical.

We have plotted consumption levels in the North and the South over time in Figure 1. The simulations confirm that regional consumption levels converge over time as proven in Lemma 1. However, notice the "bump" in North's consumption levels. As mentioned above, the incentive to reduce consumption inequality implies that consumption in the North may initially fall so rapidly that the resulting capital savings at some point must be consumed. This has the somewhat counterintuitive effect evident in Figure 1, that when inequality aversion increases from $\phi=1$ to $\phi=1.5$, the amount of time it takes for consumption levels in the North and the South to converge actually increases. However, the consumption inequality is nonetheless decreasing over time. This is in line with Proposition 2.1.

\footnotetext{
${ }^{18}$ The MatLab code used to run the simulations is available from the authors upon request.
} 

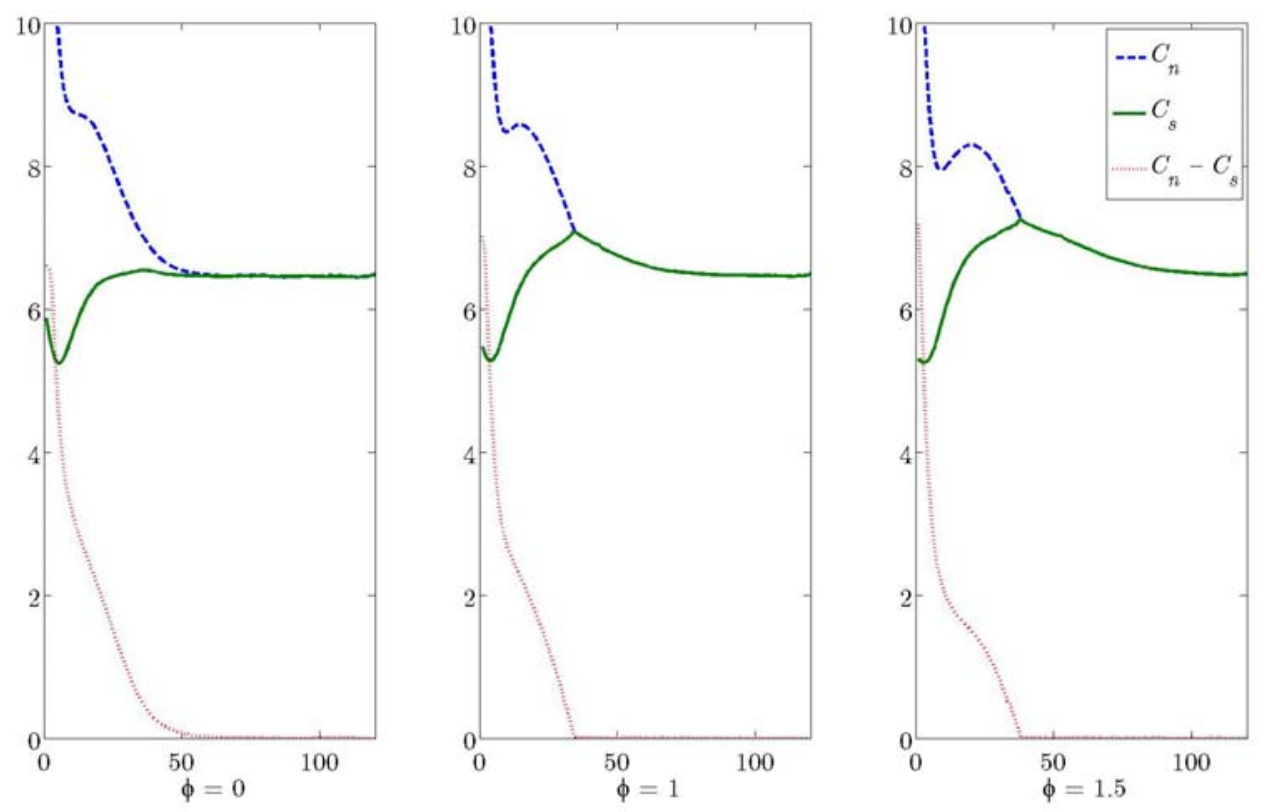

Figure 1. Consumption paths in North and South under different degrees of inequality aversion

The reason for the temporary increase in consumption around time period 20 is evident from Figure 2. This figure shows the evolution of clean and dirty capital stocks in the two regions. Note that regardless of the value of $\phi$, both types of capital converge to the same level in both regions. Hence, eventually we reach a point where: $K_{n, c}=K_{s, c}$ and $K_{n, d}=K_{s, d}$. This is as expected since first order conditions in steady state show that when regions have the same consumption levels, $\phi$ affects optimal choice variables symmetrically in the two regions. However, the paths towards steady state are clearly affected by changes in $\phi$. Note how North's accumulation of clean capital increases with $\phi$. This is because higher inequality aversion implies that North reduces consumption to reduce inequality. The savings thus accrued are invested in clean capital, which has the added benefit of yielding additional increases in the marginal utility of consumption in the South through improved environmental quality, thereby leading to a positive feedback effect.

For the same reason, inequality aversion has the exact opposite effect on the path of dirty capital in the North. To avoid reducing the marginal utility of consumption in the South, the North overshoots the reduction of the dirty capital stock relative to the steady-state level before rebuilding the stock of dirty capital when approaching this level. South responds to inequality aversion in the opposite manner, although the magnitude is much smaller. The 
higher the inequality aversion, the higher the South's accumulation of dirty capital and lower of clean capital, until capital levels converge.
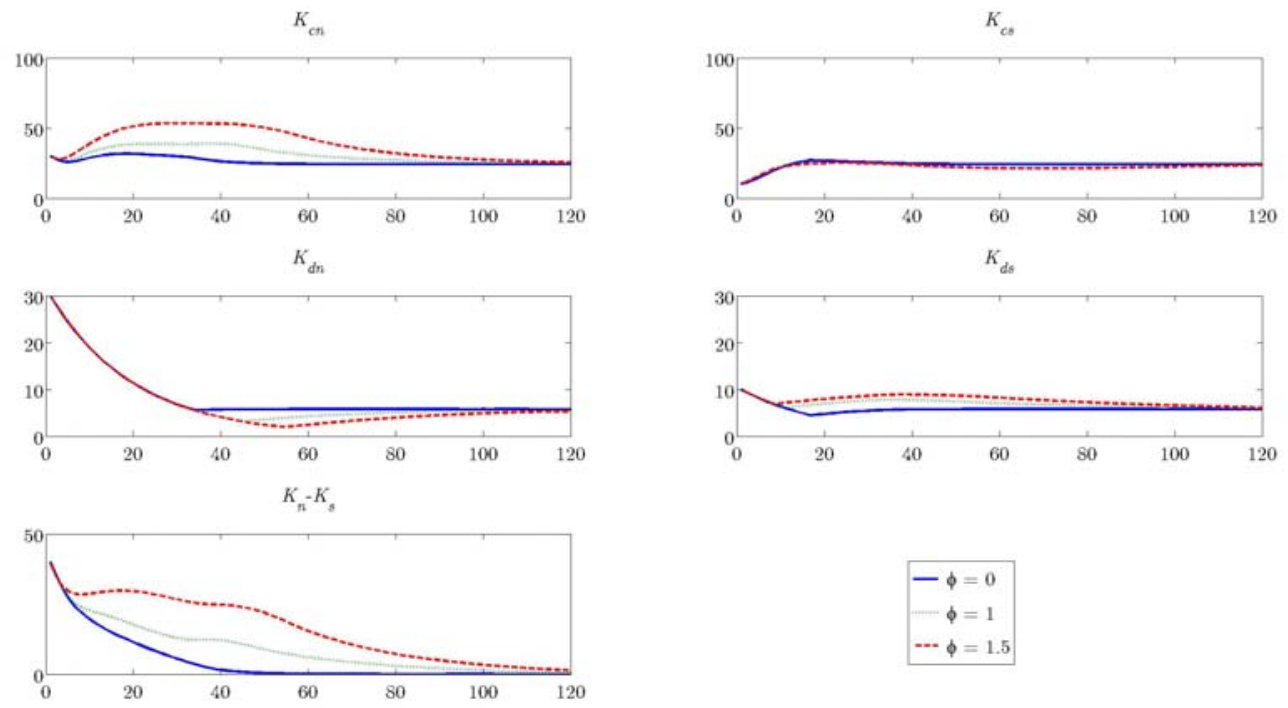

Figure 2. Time paths of clean and dirty capital under different degrees of inequality aversion

Figure 3 illustrates the effect of inequality aversion on the evolution of global environmental quality. Because of an initial increase in emissions in the South with more inequality aversion (see Figure 2), the quality of the global environment is initially lower when inequality aversion increases. The shift from dirty to clean capital takes some time, and afterward inequality aversion has an ambiguous effect on environmental quality. As time goes by, the North's disinvestment of dirty capital caused by inequality aversion dominates. Hence, over this period, environmental quality increases with higher inequality aversion. In the long run, as consumption levels converge, environmental quality is independent of inequality aversion, which again confirms our theoretical results. 


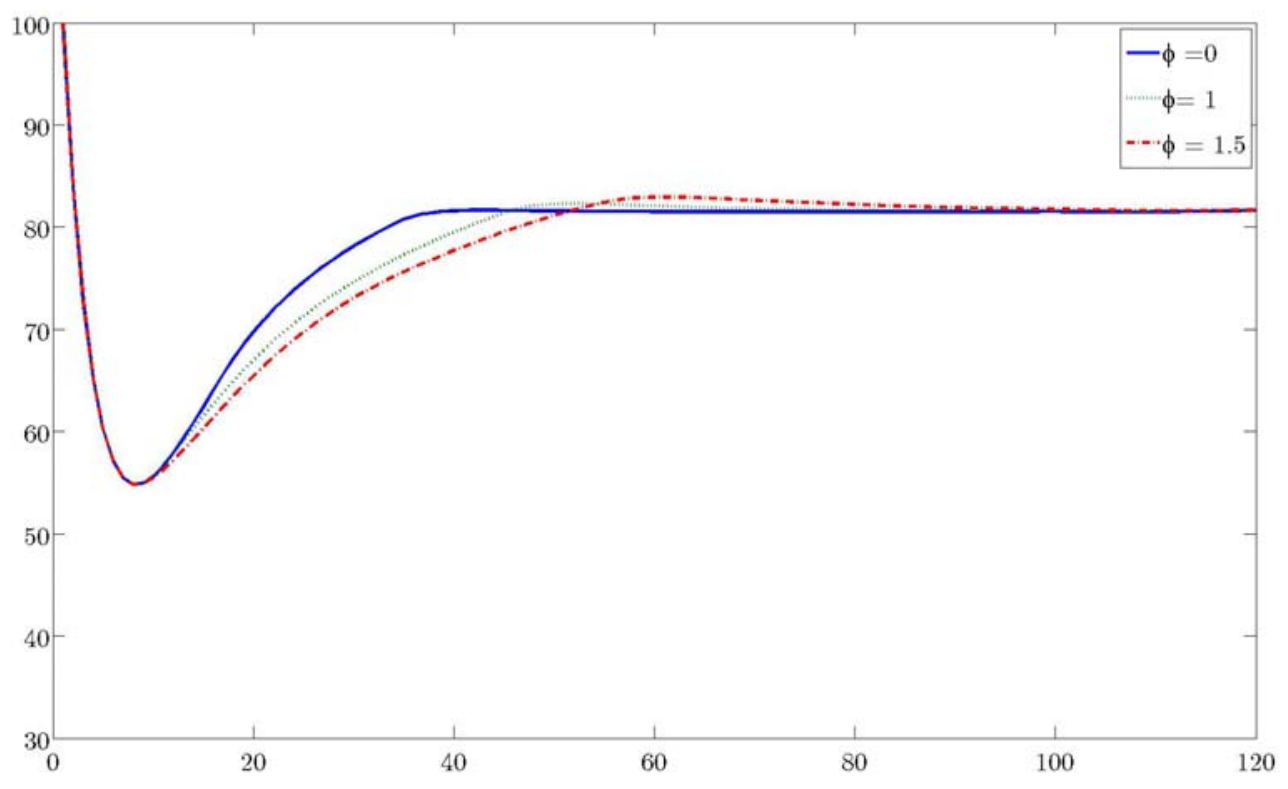

Figure 3. Time paths of the global environmental quality under different degrees of inequality aversion

\subsection{Incorporating Local Pollution in the Social Contract}

We now allow dirty capital to produce a flow of dirty pollution as described in subsection 4.2, and therefore change the utility function to:

$$
U\left(c_{r, t}, D_{r, t}, S_{t}\right)=c_{r, t}^{a} \frac{1}{\left(1+D_{r, t}\right)^{b}} S_{t}^{c} .
$$

Consumption paths are shown in Figure 4.

The consumption paths in the extended model with local pollution exhibit some surprising behavior. The consumption bump we saw in Figure 1 has now become far more dominant. With the introduction of local pollution, the bump becomes so large that convergence in consumption is no longer monotonic. The inequality in consumption actually increases for a period of time. The main reason for this is an excessive accumulation of clean capital in the North. As the South now is more reluctant to accumulate dirty capital to increase future productivity, the North invests more to reduce inequality. Again, this seemingly excessive capital accumulation must at some point turn into consumption. The fact that it may be 
optimal to postpone consumption inequality as shown in Figure 4 is caused by discounting, which makes it better to experience reduced welfare from inequality tomorrow than today. ${ }^{19}$
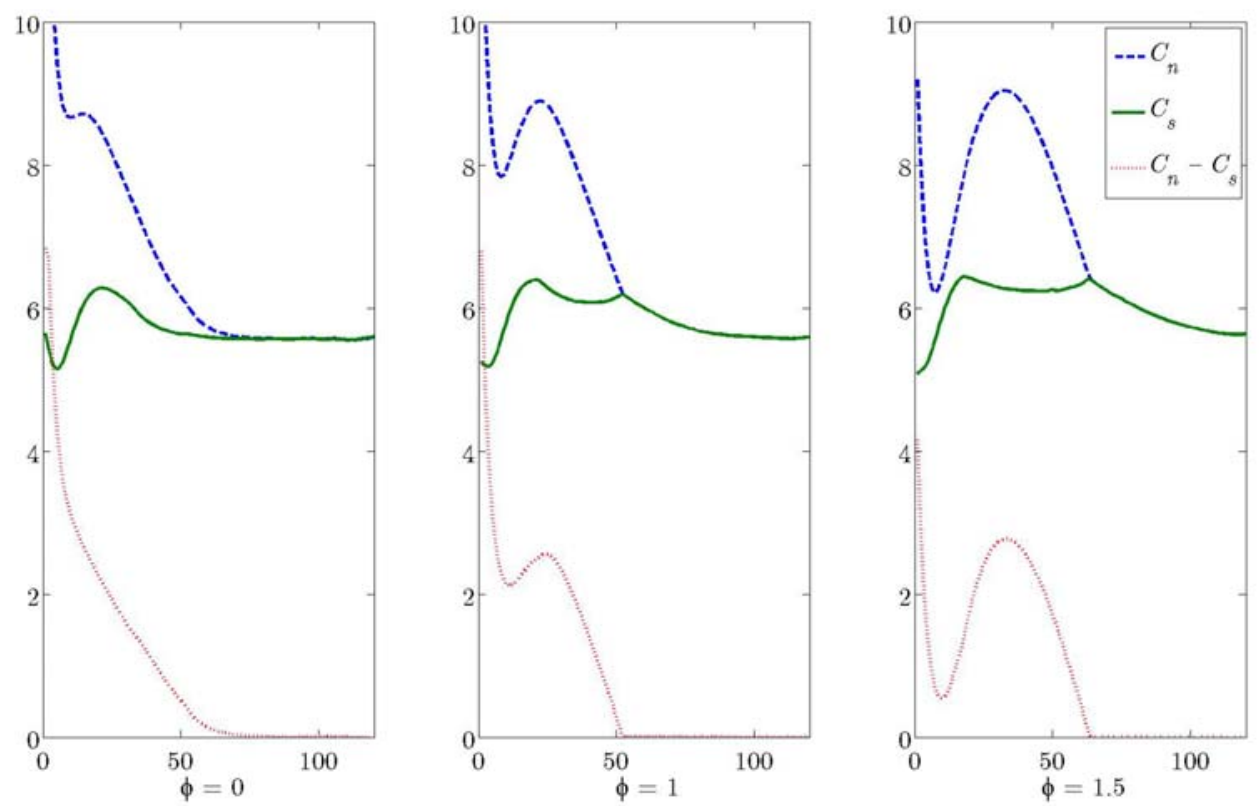

Figure 4. Consumption paths when dirty capital produces local environmental damage

Figure 5 shows capital paths for the extended model with local pollution. The capital paths for this case are similar to what we found for the base model, with differences only in the magnitudes of regional investments and disinvestments.

\footnotetext{
${ }^{19}$ This second effect has the potential to be strong enough to create a bump in North's consumption even if $\phi=$ 0 . However, it is only when $\phi>0$ that we have found that differences in consumption may temporarily increase for some time interval after consumption levels initially have been smaller.
} 

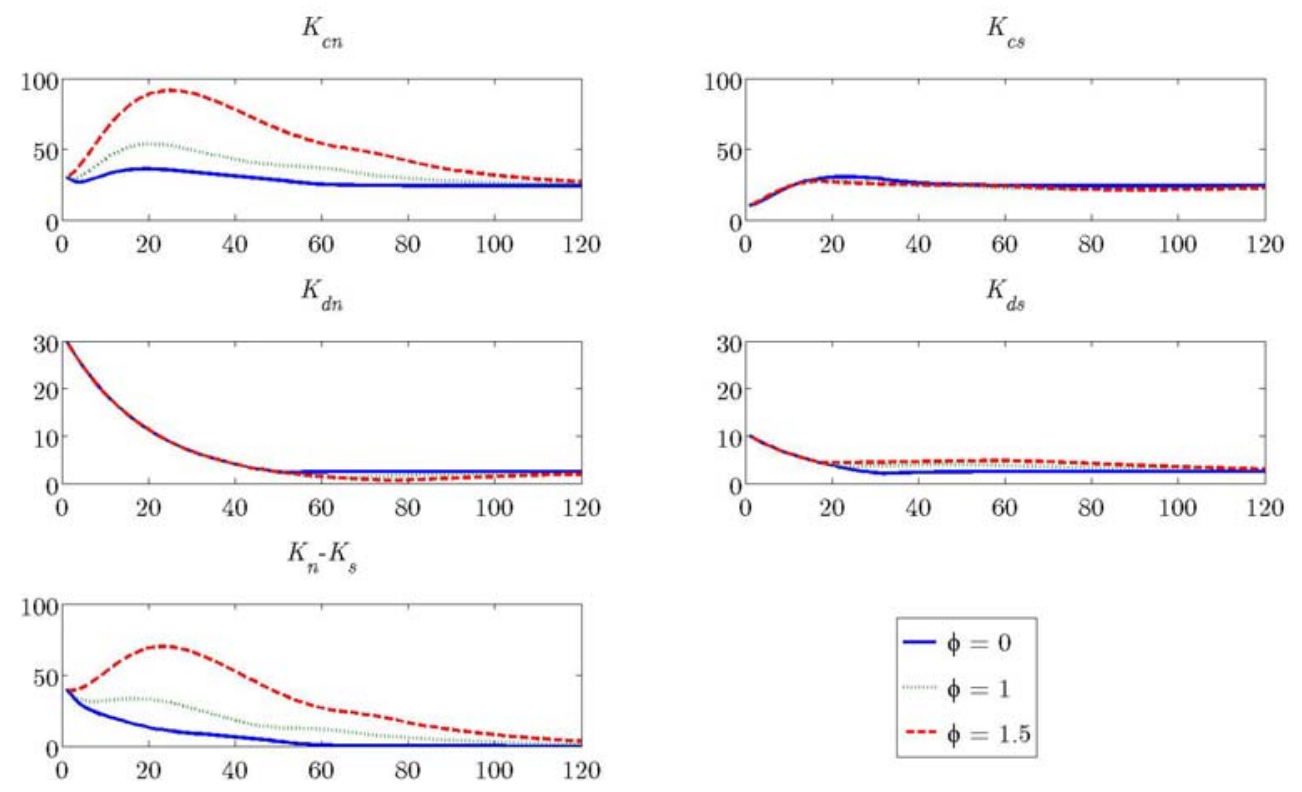

Figure 5. Time paths of clean and dirty capital when dirty capital produces local environmental damage

\section{Conclusions}

This paper studies the trade-off between intra- and intergenerational equity as represented by preferences to reduce future climate damage and to increase economic development in the poor world today. We find that inequality aversion within a generation generally will reduce consumption and greenhouse gas emissions in the rich region of the world, while consumption and emissions will increase in the poor region. This happens as the rich region shifts toward more clean capital, while the poor region is allowed to use more of the more productive dirty capital to develop faster. This result emphasizes the close relationship between development and climate policy, and justifies transferring emissions from North to South to promote economic development. This also holds when introducing monetary transfers between the regions, as well as when introducing negative effects of local pollution. Whether total greenhouse gas emissions increase as a result of income inequality aversion within a generation depends on the size of the emissions reductions in the North relative to the increases in the South.

If we consider the Kyoto Protocol in light of our findings, the division between Annex I and non-Annex I countries is justified. The first group consists of rich countries that committed to 
reducing their greenhouse gas emissions, while the latter group consists of poorer developing countries that do not have to undertake emissions reductions. Hence, the division between Annex I- and non-Annex I countries was a way to transfer wealth from North to South by imposing the use of cleaner capital in the richest region, while poor countries could use dirty but more productive capital to speed up their development. This is in line with the optimal climate policy we have characterized in this paper. The Kyoto Protocol also defines a mechanism that support capital transfers from rich to poor countries, the clean development mechanism, but does not include debt remittance or similar direct financial transfers as ways to further reduce the inequality between regions. Finally, our results suggest that poor countries should be allowed to pollute more in the short run while they catch up with the North. In the long run, however, all countries must contribute to improved environmental quality by restricting their emissions. There is no mechanism in the Kyoto Protocol to commit non-Annex I countries to reduce emissions as they become richer, but this is and should be a topic for current negotiations.

Our work suggests that future climate agreements should contain mechanisms for wealth transfers to developing countries to speed up their development and reduce inequality. These mechanisms could be in the form of lower emissions reductions for developing countries, or direct transfers, such as debt remittance or development aid. A significant step in this direction is climate finance. Under the Copenhagen Accord of 2009, developed countries have promised to provide additional climate finance of up to $\$ 100$ billion a year from 2020 to help developing countries to reduce their emissions and adapt to the consequences of climate change. There should also be explicit mechanisms that define how and when to limit the emissions of these countries as they become more developed. Moreover, our results show that in certain situations, climate agreements should require poor countries to increase their use of dirty capital in the short run to speed up their development, even if this yields higher levels of both local and global pollutants. This result is driven by the equality externality, as poor countries do not take into account the welfare loss of rich countries from inequality, and may therefore pollute too little and develop too slowly without emissions restrictions. In such situation, the developed countries can assist by funding technologies to reduce the negative effects of increased local pollution in the South. 
There are many possibilities for extending the current work. Our work abstracts from strategic considerations since all countries are assumed to be sufficiently small to take both prices and global environmental quality as given. In recent climate negotiations, it is quite clear that there are several big players in the game that exert a significant impact, both in the relevant markets and on the climate. These include large countries such as the United States and China, as well as groups of countries that coordinate their actions (e.g., the European Union). Extending our analysis to allow for strategic interaction between countries and regions therefore seems highly relevant. Another possibility for future work is to investigate the implications of limited substitutability between clean and dirty capital. While we have assumed perfect substitution between clean and dirty capital, restrictions on the substitutability may affect the results. Finally, we have not discussed impacts of technological change, which may be significant when it comes to reducing global warming. 


\section{Appendix 1: Will Consumption Levels Converge in the Long Run?}

In the long run, the economy will enter a steady state in which there will be no growth in any of the variables. We can therefore rewrite the first order conditions (11)-(15) for the steadystate levels of the variables:

$$
\begin{gathered}
\frac{\partial u\left(c_{n}, S\right)}{\partial c_{n}}-\phi=\lambda_{n} \\
c_{n}>c_{s} \Leftrightarrow \frac{\partial u\left(c_{s}, S\right)}{\partial c_{s}}+\phi=\lambda_{s} \\
c_{n}=c_{s} \Leftrightarrow \frac{\partial u\left(c_{s}, S\right)}{\partial c_{s}}-\phi=\lambda_{s} \\
\lambda_{r}\left[\frac{\partial Y_{r}\left(K_{r, c}, K_{r, d}\right)}{\partial K_{r, d}}+1-\delta_{d}\right]-\mu \kappa=\rho^{-1} \lambda_{r}, r=n, s \\
\frac{\partial Y_{r}\left(K_{r, c}, K_{r, d}\right)}{\partial K_{r, c}}+1-\delta_{c}=\rho^{-1}, r=n, s \\
\sum_{r} \frac{\partial u\left(c_{r}, D_{r}, S\right)}{\partial S}=\mu(\sigma+v) \\
S=\bar{S}-\frac{\kappa}{\sigma} \sum_{r} K_{r, d}
\end{gathered}
$$

In addition, the resource constraint must hold also in steady state: $Y_{r}=\delta_{c} K_{r, c}+\delta_{d} K_{r, d}+c_{r}$, for $r=n, s$.

From equation (50), it is clear that the long-run clean capital level must be the same in the two regions. This follows from the facts that $\rho$ and $\delta_{c}$ are the same for both countries, the production function is monotonically increasing in clean capital, and the level of dirty capital does not affect the marginal product of clean capital. Given this, condition (50) says that the marginal product of clean capital must be the same in the two regions, which implies that $K_{n, c}=K_{s, c}=K_{c}^{*}$ in equilibrium.

Next, let us consider the steady-state levels of dirty capital given by equation (49), which can be rewritten as follows:

$$
\lambda_{r}\left(\frac{\partial Y_{r}\left(K_{r, c}, K_{r, d}\right)}{\partial K_{r, d}}-\delta_{d}-v\right)=\mu \kappa, r=n, s
$$


Note that the right-hand side of this expression is the same for North and South. Using this and rearranging, we can rewrite equation (53) as follows:

$$
\frac{\lambda_{n}}{\lambda_{s}}=\frac{M P_{s, d}-\delta_{d}-v}{M P_{n, d}-\delta_{d}-v}
$$

where $M P_{r, j} \equiv \frac{\partial Y_{r}\left(K_{r, c}, K_{r, d}\right)}{\partial K_{r, j}}$ is the marginal productivity of capital $j$ in region $r$.

Let us first assume that the South never catches up with the North, so that $c_{n}>c_{s}$ in steady state. We already showed that in equilibrium the two regions have the same level of clean capital. Hence, from the resource constraint (5), we know that North must have more dirty capital than South in equilibrium to be able to consume more. This also implies that $\lambda_{n}<\lambda_{s}$ in equilibrium. However, condition (54) states that a lower shadow price of capital in the North than in the South $\left(\lambda_{n}<\lambda_{s}\right)$ requires that the marginal product of capital is higher in the North than in the South, which is not possible when $c_{n}>c_{s}$. Hence, it cannot be the case that the North consumes more than the South in equilibrium. The same reasoning can be used to rule out an equilibrium where $c_{s}>c_{n}$. Hence, the consumption levels of the two regions must converge to $c_{n}=c_{s}=c^{*}$ in the long run. This holds regardless of inequality aversion. 


\section{Appendix 2: Lagrangians to Section 4.1}

The Lagrangian in subsection 4.1.1 is:

$$
\begin{aligned}
\mathcal{L}_{s o} & =\sum_{t=0}^{\infty} \rho^{t}\left\{\sum_{r} u\left(c_{r, t}, S_{t}\right)-\phi \max \left(c_{n, t}-c_{s, t}, 0\right)-\phi \max \left(c_{s, t}-c_{n, t}, 0\right)\right. \\
& +\lambda_{n, t}\left[Y_{n, t}\left(K_{n, c, t}, K_{n, d, t}\right)-K_{n, c, t+1}+\left(1-\delta_{c}\right) K_{n, c, t}-K_{n, d, t+1}+\left(1-\delta_{d}\right) K_{n, d, t}-c_{n, t}-\tau_{t}\right] \\
& +\lambda_{s, t}\left[Y_{s, t}\left(K_{s, c, t}, K_{s, d, t}\right)-K_{s, c, t+1}+\left(1-\delta_{c}\right) K_{s, c, t}-K_{s, d, t+1}+\left(1-\delta_{d}\right) K_{s, d, t}-c_{s, t}+\tau_{t}\right] \\
& \left.+\mu_{t}\left[\sigma \bar{S}+(1-\sigma) S_{t}-\kappa_{g} \sum_{r} K_{r, d, t}-S_{t+1}\right]+\omega_{t}\left[\bar{M}-\tau_{t}\right]\right\}
\end{aligned}
$$

The Lagrangian in subsection 4.1.2 is:

$$
\begin{aligned}
\mathcal{L}_{s o} & =\sum_{t=0}^{\infty} \rho^{t}\left\{\sum_{r} u\left(c_{r, t}, S_{t}\right)-\phi \max \left(c_{n, t}-c_{s, t}, 0\right)-\phi \max \left(c_{s, t}-c_{n, t}, 0\right)\right. \\
& +\lambda_{n, t}\left[Y_{n, t}\left(K_{n, c, t}, K_{n, d, t}\right)-K_{n, c, t+1}+\left(1-\delta_{c}\right) K_{n, c, t}-K_{n, d, t+1}+\left(1-\delta_{d}\right) K_{n, d, t}-c_{n, t}-\tau_{t}\right] \\
& +\lambda_{s, t}\left[Y_{s, t}\left(K_{s, c, t}, K_{s, d, t}\right)-K_{s, c, t+1}+\left(1-\delta_{c}\right) K_{s, c, t}-K_{s, d, t+1}+\left(1-\delta_{d}\right) K_{s, d, t}-c_{s, t}+\tau_{t}\right] \\
& \left.+\mu_{t}\left[\sigma \bar{S}+(1-\sigma) S_{t}-\kappa_{g} \sum_{r} K_{r, d, t}-S_{t+1}\right]\right\}-\theta \sum_{t=0}^{\infty} \rho^{t} \tau_{t}
\end{aligned}
$$




\section{Appendix 3: Parameters Used in the Simulations}

\begin{tabular}{|l|l|l|}
\hline$A$ & Exponent in utility function (consumption) & 0.5 \\
\hline$B$ & Exponent in utility function (local environment) & 0.2 \\
\hline$C$ & Exponent in utility function (global environment) & 0.4 \\
\hline$\phi$ & Aggregate inequality aversion & $0,1,1.5$ \\
\hline$A_{c}$ & Total factor productivity in clean input production & 0.9848 \\
\hline$A_{d}$ & Total factor productivity in dirty input production & 1.2933 \\
\hline$\gamma_{c}$ & Exponent in clean input production function & 0.5 \\
\hline$\gamma_{d}$ & Exponent in dirty input production function & 0.5 \\
\hline$\delta_{c}$ & Depreciation rate of clean capital & 0.05 \\
\hline$\delta_{d}$ & Depreciation rate of dirty capital & 0.05 \\
\hline$K_{n, c, 0}$ & Initial capital stock of clean capital in the North & 30 \\
\hline$K_{n, d, 0}$ & Initial capital stock of dirty capital in the North & 30 \\
\hline$K_{s, c, 0}$ & Initial capital stock of clean capital in the South & 10 \\
\hline$K_{s, d, 0}$ & Initial capital stock of dirty capital in the South & 10 \\
\hline$\kappa_{l}$ & Local pollution per unit of dirty capital & 0.1 \\
\hline$\kappa$ & Global pollution per unit of dirty capital & 0.4 \\
\hline$\sigma$ & Regeneration rate of global environmental quality & 0.25 \\
\hline $\bar{S}$ & Initial environmental quality & 100 \\
\hline$V$ & Time preference rate & 0.05 \\
\hline$T$ & Time horizon & 150 \\
\hline & & \\
\hline & & \\
\hline
\end{tabular}




\section{References}

Acemoglu, D., P. Aghion, L. Bursztyn, and D. Hemous (2012): The Environment and Directed Technical Change, The American Economic Review, 102(1): 131-66.

Baumgärtner, S., S. Glotzbach, N. Hoberg, M. F. Quaas and K. H. Stumpf (2012): Economic Analysis of Trade-offs between Justices, Intergenerational Justice Review (1): 4-9.

Bye, B., S. Kverndokk and K. E. Rosendahl (2002): Mitigation costs, distributional effects, and ancillary benefits of carbon policies in the Nordic countries, the UK, and Ireland, Mitigation and Adaptation Strategies for Global Change, 7(4): 339-366.

Charness, G. and M. Rabin (2002): Understanding Social Preferences with Simple Tests, The Quarterly Journal of Economics, 117(3): 817-869.

Conrad, J. M. and C. W. Clark (1987): Natural resource economics - Notes and problems, Cambridge University Press, Cambridge, UK.

Dannenberg, A., B. Sturm and C. Vogt (2010): Do Equity Preferences Matter for Climate Negotiators? An Experimental Investigation, Environmental and Resource Economics, 47: 91-109.

Dasgupta, P. (2008): Discounting Climate change, Journal of Risk and Uncertainty, 37: 141169.

Fehr, E. and K. Schmidt (1999): A theory of fairness, competition, and cooperation. Quarterly Journal of Economics, 114(3): 817-868.

Glotzbach, S. and S. Baumgärtner (2012): The relationship between intragenerational and intergenerational ecological justice, Environmental Values, 21(3): 331-355.

Heal, G. (2007): Discounting: A Review of the Basic Economics, The University of Chicago Law Review, 74(1): 59-77.

Heal, G. (2009): Climate Economics: A Meta-Review and Some Suggestions for Future Research, Review of Environmental Economics and Policy, 3(1): 4-21. 
Intergovernmental Panel on Climate Change (IPCC) (2013): Climate Change 2013: The Physical Science Basis, Working Group I Contribution to the Fifth Assessment Report of the Intergovernmental Panel on Climate Change, WMO, UNEP.

Intergovernmental Panel on Climate Change (IPCC) (2007): Climate Change 2007: Mitigation of Climate Change, Contribution of Working Group III to the Fourth Assessment Report of the Intergovernmental Panel on Climate Change, Cambridge University Press, Cambridge, UK.

John, A., and R. Pecchenino. (1994). An overlapping generations model of growth and the environment. The Economic Journal, 1393-1410.

John, A., R. Pecchenino, D. Schimmelpfennig, and S. Schreft. (1995). Short-lived agents and the long-lived environment. Journal of Public Economics, 58(1), 127-141.

Kolstad, C. (2011): Public Goods Agreement with Other-Regarding Preferences, NBER Working Paper No. 17017, The National Bureau of Economic Research.

Kverndokk, S. and A. Rose (2008): Equity and justice in global warming policy, International Review of Environmental and Resource Economics, 2(2): 135-176.

Nordhaus, W. D. and J. G. Boyer (2000): Warming the World: The Economics of the Greenhouse Effect, Cambridge, MA: MIT Press.

Nordhaus, W. D. (2007): A Review of the Stern Review on the Economics of Climate Change, Journal of Economic Literature, 45(3): 686-702.

Schelling, T. C. (1992): Some Economics of Global Warming, The American Economic Review, 82(1): 1-14.

Silva, E. C. D. and X. Zhu (2009): Emissions trading of global and local pollutants, pollution havens and free riding, Journal of Environmental Economics and Management, 58: 169-182.

Stanton, E. (2011): Negishi welfare weights in integrated assessment models: the mathematics of global inequality, Climatic Change, 107: 417-432.

Stern, N. (2007): The Economics of Climate Change: The Stern Review, Cambridge University Press, Cambridge, UK. 
Tol, R., S. Fankhauser, R. Richels and J. Smith (2000): How Much Damage Will Climate Change Do? Recent Estimates. World Economics, 1(4): 179-206.

Tol, R. (2002a): Estimates of the Damage Costs of Climate Change. Part 1: Benchmark Estimates, Environmental and Resource Economics, 21: 47-73.

Tol, R. (2002b): Estimates of the Damage Costs of Climate Change. Part II: Dynamic Estimates, Environmental and Resource Economics, 21: 135-160.

Weitzman, M. (2007a): Structural uncertainty and the value of statistical life in the economics of catastrophic climate change, NBER Working Paper No. 13490, the National Bureau of Economic Research, Cambridge, MA.

Weitzman, M. (2007b): A Review of the Stern Review on the Economics of Climate Change, Journal of Economic Literature, 45(3): 703-724.

Yohe, G. W., R. D. Lasco, Q. K. Ahmad, N. W. Arnell, S. J. Cohen, C. Hope, A. C. Janetos and R. T. Perez (2007): Perspectives on climate change and sustainability, Chapter 20 in Climate Change 2007: Impacts, Adaptation and Vulnerability. Contribution of Working Group II to the Fourth Assessment Report of the Intergovernmental Panel on Climate Change, Cambridge University Press, Cambridge, UK, 811-841. 